Published in final edited form as:

Anal Chem. 2020 January 07; 92(1): 105-131. doi:10.1021/acs.analchem.9b05357.

\title{
Cell Separations and Sorting
}

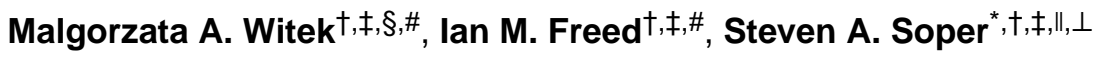 \\ tDepartment of Chemistry, The University of Kansas, Lawrence, Kansas 66044, United States \\ ${ }^{\ddagger}$ Center of Biomodular Multiscale Systems for Precision Medicine, The University of Kansas, \\ Lawrence, Kansas 66044, United States \\ $\S$ Department of Biomedical Engineering, The University of North Carolina at Chapel Hill, Chapel \\ Hill, North Carolina 27599, United States \\ "Department of Mechanical Engineering, The University of Kansas, Lawrence, Kansas 66044, \\ United States \\ ${ }^{\perp}$ Bioengineering Program, The University of Kansas, Lawrence, Kansas 66044, United States
}

\section{NEED FOR CELL SEPARATIONS AND SORTING TECHNOLOGIES}

The development of new methods and technologies for cell separation, sorting, selection, isolation, or enrichment (many times the aforementioned terms are used interchangeably) are becoming more imperative due in part to the wealth of research aimed at addressing issues for the analysis of liquid biopsy targets, such as rare cells, to realize the concept of "precision medicine". Precision medicine is defined as "treatments targeted to the needs of individual patients on the basis of genetic, biomarker, phenotypic, or psychosocial characteristics that distinguish a patient from others with similar clinical presentations." Before full implementation of precision medicine in a hospital or clinical setting, technological discoveries must be realized to assist in the analysis of disease-associated cells enriched from complex samples.

Liquid biopsy markers and the cargo that they carry have been shown to be an attractive source of information that can be used to facilitate precise decisions for disease management. These biomarkers include, but are not limited to, rare cells such as circulating tumor cells (CTCs) or cancer stem cells (CSCs), immune cells (i.e., CD8+ T-cells), bacterial and viral cells, cell-free molecules such as cell free DNA (cfDNA), and extracellular vesicles (EVs). Liquid biopsies are attractive because of the minimally invasive nature of the sampling method (i.e., collection of peripheral blood, urine, saliva) to secure relevant biomarkers. These biomarkers can enable precision medicine decisions on managing a variety of diseases, including oncology and nononcology-related diseases. ${ }^{2,3}$ Liquid biopsies

\footnotetext{
*Corresponding Author: ssoper@ku.edu.

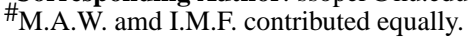

Notes

The authors declare the following competing financial interest(s): S.A.S. holds equity shares in BioFluidica, Inc., a company that holds commercialization rights to CTC isolation technology presented herein. M.A.W. declares a conflict of interest as a spouse of a BioFluidica, Inc. employee. I.M.F. declares no conflict on interest.
} 
allow for more frequent sampling ${ }^{4}$ over long periods of time when compared to traditional solid tissue biopsies. Therefore, clinical oncology has focused on investigating the ability of liquid biopsies to provide equivalent or further information to clinicians than is currently received from solid tissue analysis or imaging. The biomarker needs to provide actionable information by indicating disease recurrence, progression, or survival to help guide treatment decisions. ${ }^{5}$

As stated, although terms such as cell sorting, separation, enrichment, or isolation are often used interchangeably, for clarity we define two types of cell isolation/enrichment processes: (i) cell separations (i.e., isolation), which are predicated on the enrichment of cells from samples that utilize a batch-type approach. An example here would be affinity-based approaches in which target cells are selected from a sample using surface immobilized antibodies, aptamers, or peptides. Once the target cells are enriched from the sample, they can be either analyzed directly on the surface to which the affinity agent is attached or released to allow for subsequent analysis such as molecular profiling.

The second type of cell isolation process is cell sorting, which continuously monitors either a physical or biological property of a cell contained in a sample and directs the relevant target cells to a receiver. A good example of a cell sorter technology is flow assisted cell sorting (FACS) in which cells contained in a biological sample are labeled with a reporter and following interrogation online using a laser, are directed into a receiving reservoir for analysis. For cell sorting, the identification process of the target cell(s) can be based on a physical property of the target cell (i.e., size, density) or biological property (i.e., expression of a particular antigen).

Upon inspection of the literature, it became apparent that one of the most reported application for cell sorting or separation involves CTCs. Numerous methods and platforms have been developed to specifically provide enrichment of CTCs. CTCs are shed from a primary tumor or micro/macro-metastatic sites and released into blood circulation initiating metastasis in distant organs. These cells are extremely rare or not detected at all in healthy or nonmalignant disease. ${ }^{6}$ Numerous studies have assessed CTCs for clinical use; $;{ }^{7,8}$ a search of Web of Science over the period between 2017 and 2019 produced more than 11000 publications mentioning "CTC" in their title or in the main text of the article. The review presented herein, however, will focus on technologies for the selection of other "low abundant" cells, immune cells, or bacterial cells using either separation and/or sorting techniques. The reviewed literature highlighted in this review covers the time frame from September 2017 to September 2019.

As will be shown in this review, many isolation technologies select cells of interest based on biological or physical properties of the target cells to discriminate them from other, more abundant red blood cells (RBCs) or white blood cells (WBCs) when blood is the sampling milieu. Biological properties for selection can be defined as the expression of a unique antigen not expressed in other blood components. In the case of CTCs, new antigens are being explored for selection in addition to the well-recognized surface protein, epithelial cell adhesion molecule (EpCAM). Technologies employing physical properties, on the other hand, seek to discriminate CTCs and other cells based on size, deformability, density, or 
dielectric properties, among others. Some technologies can exploit a combination of both biological and physical properties.

The primary challenge in CTC analysis has been the low abundance of CTCs (1-3 000 CTCs $/ \mathrm{mL})^{9}$ against a high background of blood cells $\left(10^{9} \mathrm{RBCs} / \mathrm{mL} ; 10^{7} \mathrm{WBCs} / \mathrm{mL}\right) .{ }^{10}$ CTCs must be discerned by a unique property that specifically differentiates CTCs from blood cells to affect favorable selection operational metrics, such as recovery and purity.

It will also become apparent from this review that as precision medicine matures, there is a need to not just "enumerate" the markers, such as cells from clinical samples, but also analyze their molecular cargo (i.e., DNA, mRNA) to guide treatment decisions, provide information as to the best treatment options for a patient, determine if the patient is responding to treatment, secure information on disease recurrence, and/or identify bacterial cells and their antibacterial resistance. The challenge with liquid biopsy markers in terms of their molecular analysis is the mass limits (i.e., nucleic acids copy number) they impose on the molecular assay. ${ }^{11}$ For example, it is not uncommon to detect a single cancer cell (i.e., CTC) per $\mathrm{mL}$ of blood. Within this 1 CTC there are 2 copies of each chromosome with a genomic (g)DNA mass of $\sim 6 \mathrm{pg}$ and about $1 \mathrm{pg}$ of mRNA. ${ }^{12}$ While amplification of the DNA via PCR or reverse transcription of the mRNA followed by PCR can be used to increase the copy number of the nucleic acids, issues may arise with amplification bias resulting in poor representation of the genome, masking epigenetic modifications, and potential false results due to polymerase errors.

We present in this review technologies that addressed these challenges. ${ }^{13,14}$ We will review methods that merge cell enrichment methods with downstream applications such as RNA and DNA sequencing. ${ }^{15-18}$ The difficulties with the analysis of proteins harvested from a limited number of selected cells also exists, owing to the limit-of-detection of molecular analysis methods used for protein profiling and the lack of techniques for the amplification of proteins. Challenges of existing approaches that cannot handle subattomole quantities of proteins isolated from minute numbers of cell lysates were addressed by reports highlighted in this review. ${ }^{19}$

In view of the needs and challenges associated with downstream analysis of the molecular cargo of enriched cells, we wish to point out that there are metrics that can compare the utility of different cell isolation methodologies. These "figures-of-merit" include (i) ability to efficiently recover the cell(s) of interest, (ii) aptitude to select high-purity cell populations, and (iii) process large samples in a high-throughput fashion to efficiently search for rare cells.

Even though CTCs hold a strong presence with respect to isolation and enrichment platforms, there are other type of cells for which novel platforms were demonstrated. For example, technologies were presented for the screening and analysis of bacterial cells, ${ }^{20-27}$ yeast cells, ${ }^{28,29}$ immune cells, ${ }^{30,31}$ or characterization of red blood cells. ${ }^{32,33}$ This review will cover methods for cell separation and sorting based on numerous phenomena, such as acoustophoresis, affinity, dielectrophoresis and inertial forces, size and elasticity, deterministic lateral displacement, flow fractionation, and density gradient centrifugation. 
We cover in this review magnetic, impedance, and fluorescence-activated cell sorters as well as droplet-based methods. A part of this review will also consist of methodologies based on image processing for guided particle sorting, such as optofluidic sorters.

\section{CELL SEPARATION METHODS}

\section{Affinity and Adhesion-Based Separations.}

By utilizing different ligands and substrates, highly specific affinity interactions can be used for cell isolation. Commonly used affinity selection methods involve taking advantage of specific and strong antibody-antigen interactions, in which particular cells can be targeted by examining surface antigens they possess, and functionalizing solid phases, such as a microchannel surface or magnetic beads, with an antibody for enrichment of a target cell from a sample. Microfluidic devices afford high surface area-to-volume ratios, enabling the opportunity for enhanced cell-wall interactions, hence, highly efficient recovery of rare cells. As noted previously, these are considered cell separations because the cells are captured by the affinity agents in a batch mode and following enrichment can be released from the platform.

With affinity-based separations, it is important to understand cell biology because cells are not static and can undergo transitions causing down regulation of potential targeting antigens used for enrichment of particular cells. For example, EpCAM is well recognized to be expressed by cancers of epithelial origin; however, evidence suggests the heterogeneous nature of CTCs stems from the epithelial-to-mesenchymal transition (EMT) that produces mesenchymal CTCs. An in vitro model of EMT was developed to show that EMT-induction decreased EpCAM expression and as a result lower sensitivity of anti-EpCAM based recovery of cells. The researchers suggested that for CTC capture, targeting cells with EGFR antigens rather than EpCAM may be more robust, specifically in light of EMT, providing valuable insight for potential affinity-based separation methods. ${ }^{34}$

CellSearch utilizes anti-EpCAM-functionalized magnetic beads to isolate CTCs from blood. A recently developed microfluidic device utilized a similar magnetic nanoparticle-based approach. ${ }^{35}$ The device stratified CTCs into different on-chip zones using magnetic forces to isolate CTCs based on their EpCAM expression levels. Blood was incubated with magnetic nanoparticles functionalized with anti-EpCAM antibodies, and targeted cells were stoichiometrically labeled with particles according to the number of EpCAM protein molecules on their surface. X-shaped structures in a microfluidic device created low-flow regions to increase CTC capture in the presence of a magnetic field. ${ }^{35,36}$ Cells experienced lower velocity as they moved through the device with an expanding cross-sectional area. The magnetic force applied to the cells was proportional to the amount of nanoparticles bound to the EpCAM-expressing cells. Cells with a higher EpCAM expression level experienced higher magnetic forces and were trapped in the early zones of the device, whereas cells with lower EpCAM expression were trapped in later zones. This microfluidic device was able to detect CTCs in $86 \%$ of tested clinical patient samples compared to $60 \%$ with CellSearch. ${ }^{35}$

Kang et al. ${ }^{37}$ demonstrated a dual-immunopatterned (DIP) microfluidic device fabricated for the simultaneous capture of both epithelial and mesenchymal CTCs utilizing anti-EpCAM 
antibodies and newly developed anti-63B6 antibodies (Figure 1A). The DIP device consisted of a circular chamber, where an inlet and four outlets were located at the center and the edge of the chamber. The chamber was formed by aligning two similarly designed layers each with evenly spaced rings and an array of microposts. The rings were alternately formed from the upper and bottom layers having a different antibody coated and spaced $135 \mu \mathrm{m}$ apart ultimately forming four zones consisting of 20 rings each. The device also contained zones with differing pressure under steady flow rates, which allowed for the profiling of CTCs based on surface protein expression levels. A recovery of $95 \%$ was reported.

Dasanna et al. ${ }^{38}$ simulated the effects of shear rates and inclination angles of P-selectin adhesive stripes in a microfluidic device to investigate the enrichment of WBCs from RBCs. Interplay between microscopic bond dynamics from leukocytes sticking to the adhesive stripes and macroscopic determinants such as shear rate and viscosity afforded dynamic states such as free flow, rolling, and transient adhesion. The relationship between these states were in good agreement with experimental results for the isolation of WBCs from whole blood on P-selectin patterned chips. Additionally, the authors used the simulations to investigate the separation of three different stages of malaria-infected RBCs.

Inspired by the nonfouling nature of the outer membrane of RBCs, Li et al. ${ }^{39}$ synthesized copolymer micelles with RBCs' cell outer membrane and zwitterion interface. The so-called cell membrane mimetic micelles demonstrated lack of bioadhesion in the body; however, when modified with folic acid (FA) and an arginine-glycine-aspartic acid (RGD) peptide, they exhibited affinity for folate receptor (FR) overexpressed on tumor cells (Figure 1B,C). Cell membrane mimetic surfaces (CMMS) repelled blood cells at $>99.999 \%$, while targeting CTCs via ligands tethered to the surface to enable cancer cell capture provided $91 \%$ recovery and $89 \%$ purity. ${ }^{39}$

A recent paper by Chen et al. ${ }^{40}$ showed that lateral filter array microfluidics (LFAM) and immunoaffinity can be combined into one device to accomplish CTC isolation from bufferdiluted blood. The device captured spiked in model CTCs and clinical CTCs with and without antibody functionalization. The array had five zones of lateral filters for a total of 13 600 filters with sizes between 6 and $10 \mu \mathrm{m}$. The filters were fabricated in a parking-spacelike arrangement, which allowed automatic flow adjustment if a filter space was occupied by a CTC. Simulations were performed to find the optimal flow rate at which fluid passed through every array. Without functionalization, capture efficiency of a pancreatic cancer cell line varied between 70 and $84 \%$. With anti-EpCAM functionalization, capture efficiency improved to $99 \%$ at a flow rate of $1.8 \mathrm{~mL} / \mathrm{h}$, with low nonspecific binding of WBCs.

A flow-based microfluidic device was developed by Birmingham et al. ${ }^{43}$ to investigate metastasis via adhesion separation. Cells were perfused over a microfluidic channel bed functionalized with E-selectin. Residence time was used as a measure for cellular adhesive behavior to separate cells into two discrete fractions: adhesive and free-flowing. The device demonstrated that increased adhesion correlated with enhanced metastatic potential in LS174T colon carcinoma cells, affording the opportunity to better understand cancer metastasis. ${ }^{43}$ 
A microfluidic device with anti-EpCAM and anti-CD133 antibodies functionalized to its surface was utilized to isolate epithelial CTCs and those with cancer stemlike characteristics (CSCs) from pancreatic ductal adenocarcinoma (PDAC) patient blood samples. It was discovered that $84 \%$ of patients had detectable levels of EpCAM(+) CTCs, while CD133(+), indicative of CSC character, were detected in 7 out of 10 patients. ${ }^{44}$ Zeinali et al. ${ }^{41}$ also utilized both anti-EpCAM and anti-CD133 antibodies to isolate subpopulations of CTCs from the peripheral blood of PDAC patients. The CTC Carpet Chip contained $\sim 80000$ microposts and enabled $>97 \%$ recovery of cancer cells spiked into whole blood with $76 \%$ purity (Figure 1D,E).

Sinusoidal microfluidic devices ${ }^{42}$ were used for the affinity selection of circulating plasma cells (CPCs) from patients diagnosed with plasma cells disorders (Figure 1F), such as multiple myeloma. Using anti-CD138 antibodies covalently attached to the sinusoidal microfluidic chip's surfaces, CPCs from blood of patients diagnosed with monoclonal gammopathy of undetermined significance (MGUS), symptomatic or active multiple myeloma were recovered with 70\% efficiency. The isolated CPCs were then assessed for $K R A S$ mutations using polymerase chain reaction (PCR), ligase detection reaction (LDR), and capillary gel electrophoresis (CGE) and tested for chromosomal abnormalities via fluorescence in situ hybridization (FISH).

Kim et al. ${ }^{45}$ used graphene oxide as a substrate material for antibody surface conjugation, as it affords a high density of surface-functionalized antibodies, making a microfluidic device capable of detecting low numbers of CTCs from blood $(73 \pm 32 \%$ at $3-5$ cells $/ \mathrm{mL}$ blood; $87 \%$ for 100 spiked cells $/ \mathrm{mL}$ ). The device was able to detect at least $1 \mathrm{CTC} / \mathrm{mL}$ in $89 \%$ of metastatic breast cancer patients. Captured CTCs were analyzed using immunofluorescence and transcriptional analysis.

Aptamers were shown as affinity capture agents in work by Reinholt et al. ${ }^{46}$ The cell-capture microchannel was functionalized with aptamers and cells were directed toward a micropillar array to enhance CTC capture. By performing cell capture and lysis on one device, sample loss and contamination were significantly reduced. Sample was first flowed toward the CTC capture array for cell separation. After separation, the flow direction was changed orthogonal to the capture array and lysis buffer was introduced into the chip. Captured cells were lysed and their contents flowed toward a second array for the physical entanglement of gDNA. After entanglement, gDNA was amplified and prepared for the identification of point mutations.

Field-effect transistors (FETs) can be useful biosensors for cellular detection. Chen et al. ${ }^{47}$ was able to integrate high-specificity aptamer-functionalized FETs with cell trapping devices in order to affinity capture cancer cells for enumeration with an automated process on a microfluidic device at a flow rate of $90 \mu \mathrm{L} / \mathrm{min}$.

In an effort to improve on CTC isolation, many studies utilized negative selection to enrich CTCs. Negative selection is performed by targeting leukocytes with anti-CD45 antibodies to deplete WBCs. This CTC isolation method reported by Liao et al., ${ }^{48}$ who integrated negative 
CTC selection with subsequent spheroid cell culture to increase cancer cell purity up to $34 \%$, compared to $<10 \%$ for other negative affinity-based methods. ${ }^{48}$

Release of captured cells are an important part of any CTC separation assay, which uses a batch type approach to enrich cells from a mixed population. A recent development for enriched cell release has been made that utilized affinity capture with antibodies conjugated to a photodegradable poly(ethylene glycol), PEG, hydrogel cell capture surface. Cells were captured with an efficiency of $13.4 \%$ from whole blood and were selectively released from the surface by irradiation with UV light allowing for bulk or individually targeted release from the surface while maintaining viability above $90 \% .49$

\section{SORTING METHODS}

\section{Acoustofluidic- and Acoustophoretic Cell Sorting.}

Acoustofluidics employ ultrasonic waves generated by interdigitated transducers (IDTs) on a piezoelectric material that is integrated to a microfluidic device. These waves can propagate into a fluid in the form of surface acoustic waves (SAWs) creating different inertial and fluid velocities. ${ }^{50}$ Several new microfluidic designs have been recently developed that take advantage of acoustofluidics for cell sorting.

A new design introduced by $\mathrm{Wu}$ et al. ${ }^{51}$ used tilted-angle SAWs and provided significant improvement in the throughput of the acoustic sorting method (Figure 2A). The design increased acoustic energy density by using a hybrid PDMS-glass channel, while simultaneously increasing CTC sorting efficiency to $86 \%$ at a throughput of $7.5 \mathrm{~mL} / \mathrm{h}$. The device isolated CTCs from clinical prostate cancer patient blood, which were subsequently immunophenotyped for confirmation of CTC isolation. The device also contained a PDMS divider present within a microchannel. In a straight channel, the velocity distribution is parabolic, but with this PDMS divider, the velocity of cells in the center of the channel was lower than those toward the walls. This velocity decrease afforded more time for the acoustic radiation forces to act upon cells, which allowed for better differentiation between CTCs and WBCs due to lateral displacement.

The same research group reported throughput for a single, enclosed microfluidic device at $500 \mu \mathrm{L} /$ min achieving simultaneous sorting of 10,12 , and $15 \mu \mathrm{m}$ particles. At $\sim 85 \%$ purity, WBCs were sorted from RBCs and CTCs from WBCs utilizing novel three-dimensional acoustofluidic tweezers (3D-AFT) (Figure 2B). The 3D-AFT balanced fluidic drag forces with acoustic radiation to achieve particle/cell focusing in three dimensions. Particles were first directed into an asymmetric serpentine channel, where lift forces were dominant and aligned particles/cells into a single lateral stream. To accomplish alignment in the vertical direction, an acoustic focusing resonator was implemented to create pressure nodes that vertically align particles/cells. The size of the particle or cell along with the input power determined the deflection distance, which could be exploited for sorting. ${ }^{52}$

Gnyanwali et al. ${ }^{53}$ combined both ultrahigh frequency ultrasound (US) backscatter and laser-induced photoacoustic (PA) waves to accomplish a high throughput label-free analysis of single cells with a microfluidic device. US backscatter results from an acoustic impedance 
differential between a cell and the surrounding medium, while PA waves are generated from optical absorption of the cell creating a rapid thermo-elastic expansion that caused broadband mechanical waves at ultrahigh frequency. The US transducer was integrated to a PDMS microfluidic device and was triggered simultaneously with a laser. The laser excited the particle first, generating a PA wave, and $~ 900$ ns later, a US pulse scattered off the particle or cell. Particles/cells could be differentiated by their generated backscatter and/or PA waves. RBCs, for example, absorb light at $532 \mathrm{~nm}$ and generate a strong PA signal. The device (Figure 2C) could identify and count RBCs and WBCs at a throughput of 150 cells/min similarly to a conventional fluorescence-activated cell sorting (FACS) system without the adverse effects of buffers required for RBC lysis, which can alter membrane permeability.

By combining IDTs and focused IDTs (FIDTs) to produce both standing surface acoustic waves (SSAWs) and traveling surface acoustic waves (TSAWs) (Figure 2D,E), Wang et al. ${ }^{54}$ recovered $90 \%$ of glioma cells from blood. SSAWs were produced from the interference of SAWs propagating in opposite directions. These SSAWs have a one-dimensional periodic distribution of pressure nodes and antinodes. Particles and cells can be trapped at these pressure nodes, which can be used to align particles/cells into lines. The SSAWs act as a focusing module for the particles or cells without need for a sheath flow. The FIDTs produce TSAWs to push tumor cells away from RBCs. The energy of TSAWs is concentrated at a focal point with high spatial resolution, and particles or cells will experience a sizedependent unidirectional force in an acoustic traveling wave field, which pushes particles or cells along the direction of TSAW propagation. Wang et al. also demonstrated sorting of 5 $\mu \mathrm{m}$ diameter and $2 \mu \mathrm{m}$ diameter particles using the same device. ${ }^{54}$

In a study reported by Gonzalez et al., ${ }^{6}$ a new strategy of utilizing plate acoustic waves (PAW) was demonstrated in a report that sorted tumor cells from WBCs in a microfluidic device with approximately $84 \%$ recovery and $80 \%$ purity. The device was actuated by plate vibrations from a single SU-8 based piezoelectric transducer, allowing the opportunity to utilize lower operating frequencies and lower manufacturing costs compared to traditional bulk acoustic wave devices, and also overcame physical restrictions of IDTs. This chipbased sorting relied on the generation of typical vibration modes of a plate that generated pressure nodes within the microfluidic channel at desired locations. The geometry of the chip gave a large surface/volume ratio and, together with the thickness being slightly smaller than a quarter of the generated wavelength, provided the platelike actuation of the plastic device. $^{56}$

Garg et al. ${ }^{57}$ reported on Lateral Cavity Acoustic Transducers (LCATs), which utilized trapped bubbles that acted as acoustic microstreaming sources. The oscillation of the bubbles was accomplished by an acoustic energy source allowing LCATs to simultaneously accomplish bulk pumping and size-based sorting of particles in solution for the sorting of platelets, RBCs, and WBCs. Rapid on-chip immunolabeling was done to verify captured cell identity; the device generated $\sim 100 \%$ efficiency with a $200 \times$ enrichment ratio from a $20 \mu \mathrm{L}$ sample. 
The work of Shamloo et al ${ }^{58,59}$ presented a considerable amount of simulation and modeling in an effort to optimize design specifications for efficient sorting of various blood particles in both rectangular and trapezoidal acoustofluidic devices. Applied voltage simulations were performed to determine a voltage domain in which the cells could be sorted with maximum efficiency. Numerical studies of SSAWs should be considered in the future for IDT geometrical factors, channel geometry, or tilted angle waves to analyze the sorting process.

Acoustophoresis is emerging as a highly promising technique for cell sorting. One work utilized size-independent acoustic impedance to sort CTC model cells (i.e., cell lines) from peripheral blood mononuclear cells (PBMCs) in $1 \mathrm{~h}$ with $>86 \%$ recovery and $>50$-fold enrichment. This was accomplished by infusing two fluids into a channel, a suspending medium with an acoustic impedance matching that of PBMCs and a sheath fluid with a higher or lower impedance than that of CTCs. Depending on their impedance, CTCs were able to migrate into the higher or lower impedance fluid (Figure $2 \mathrm{~F}$ ). 55

Affinity size amplifiers were presented by Liu et al. ${ }^{60}$ to improve sorting efficiency via acoustofluidics. Gelatin-coated $40 \mu \mathrm{m} \mathrm{SiO} 2$ microbeads were grafted with an anti-EpCAM antibody containing gel, allowing for selective affinity capture of CTCs. The microfluidic device then used TSAWs to sort the affinity-captured CTCs from normal blood cells based on size-dependent responses to the administered acoustic waves. Recoveries of $77 \%$ and purities of $96 \%$ were reported. Captured CTCs were released (96\% efficiency, $83 \%$ viability) from the microbeads via degradation of the gelatin coating for downstream analysis.

TSAWs have been combined with inertial flow focusing for a microfluidic device that was able to generate high purity (>90\%) and viability (>90\%) while sorting cells at rates comparable to conventional FACS instruments. Inertial flow focusing is used to order the cells into a single file, while a laser interrogates cells for fluorescent signals at the output and sorts cells via IDT-generated TSAWs at rates up to 5000 events per second. Sorting experiments in an injection buffer similar to cell culture media involved staining $10 \%$ of infused cells with calcein AM as a fluorescent label and were sorted from nonlabeled cells. 61

Coupling of $\mu$ FACS with SSAWs was demonstrated by Ren et al. ${ }^{62}$ who were able to sort mammalian cells with $>90 \%$ purity at 2500 cells/s. A single-layer microfluidic device integrated an in-plane optical fiber detector and two separate IDTs, one for cell focusing and the other for cell deflection. Cells were first focused, then analyzed by the optical fiber system, and subsequently deflected into collection or waste receiver wells.

\section{Inertial and Lift-Force Cell Sorting.}

Inertial microfluidic devices allow for the principles of inertial migration and Dean Flow to be exploited. High flow rates can be achieved that afford precise methods for cellular sorting. A common method for inertial sorting involves the use of spiral microchannels, and many groups have taken to its utilization. 
Lee et al. ${ }^{63}$ used a spiral channel to sort mesenchymal stem cells from mouse bone marrow with a recovery of $73 \%$ at a flow rate of $1.6 \mathrm{~mL} / \mathrm{min}$. The sorting resulted in the integrity of the cells being preserved, retaining high viability (>95\%) and maintaining their phenotype compared to nonprocessed cells. Kwon et al.$^{64}$ utilized spiral inertial microfluidics to sort viable from nonviable cells. Spiral microfluidic assays for label-less sorting of cells demonstrated up to $28 \%$ dead cell removal efficiency and $~ 99 \%$ live cell retention efficiency, despite the size overlap between viable and nonviable Chinese hamster ovary cells. By multiplexing the device to four spirals, the device was able to achieve the removal of small nonviable cells at cell concentrations of 10 million cells $/ \mathrm{mL}$ with a throughput of $6-8 \mathrm{~mL} /$ $\min$.

Another example was demonstrated for the isolation and detection of exfoliated bladder cancer cells (EBCCs) from urine samples with inertial focusing microfluidics, which afforded $93 \%$ sensitivity. Isolated cells were further analyzed downstream and confirmed for the presence of EBCCs. ${ }^{65}$ Spiral inertial microfluidics were also utilized to sort full thickness chondrocytes into superficial, middle, and deep zone chondrocyte subpopulations based on size and enabled enrichment for potential clinical use for chondrocyte implantation. ${ }^{66}$

Tay et al. ${ }^{47}$ exploited the fluid mechanics of spiral devices to afford size sorting of PBMCs into monocytes, lymphocytes, and platelets with a purity of $\sim 90 \%$ in a rapid $(130 \mu \mathrm{L} / \mathrm{min})$, continuous, and label-free manner. A study investigated the ability of spiral inertial focusing to sort fungal cells from WBCs after RBC lysis. Recovery of $8.4 \%$ for spiked fungal cells at $400 \mu \mathrm{L} / \mathrm{min}$ was demonstrated, showing that inertial spiral focusing could have clinical significance as a qualitative device for quickly assessing the presence of fungal cells in blood. ${ }^{67}$

Syverud et al. ${ }^{68}$ developed a device deemed "Labyrinth", containing 11 loops and 56 corners to sort individual streams of cells with differing sizes at a throughput of $1.8-2.5 \mathrm{~mL} / \mathrm{min}$. The Labyrinth utilized inertial forces as a focusing element for particles, while drag forces from Dean flow enabled particle migration away from the center of a channel. The major difference between the Labyrinth and similar devices is that the Labyrinth design employs numerous sharp corners placed across the flow pattern. The idea is that these corners are "sharper" than traditional loops, enabling the enhancement of Dean forces to migrate particles toward their equilibrium positions. This device was able to sort skeletal muscle satellite mouse and rat cells from fibroblasts with purities up to $78 \%$. Cells were then cultured for 2 weeks to assess structural development. A microfluidic device allowed for the sorting of CTCs followed by single-cell isolation. The technique combines two chips, one to utilize inertial microfluidics for sorting CTCs from blood, followed by a second chip for hydrodynamic focusing to trap single cells. The device was able to process $7.5 \mathrm{~mL}$ of blood in under 45 min with $>90 \%$ CTC isolation efficiency. ${ }^{69}$

Hazra et al. ${ }^{70}$ developed a device that utilized lift forces from the interfacial tension of a liquid-liquid interface to enable label-free sorting at a low Reynolds number $(\operatorname{Re}<1)$ based on size and stiffness of cancer cells. Aqueous dextran and PEG were infused into the device to form a stable interface. Particles present in either phase experience different noninertial 
lift forces due to deformation in the flow field, interfacial tension force at the interface, and viscoelastic lift force. The device operated in the Stokes regime, where deformable objects experience noninertial lift. The magnitude of this force depended on the particle location with respect to the wall. Because noninertial lift force is a function of deformability of the object, similarly sized objects of differing elasticity can be sorted. Essentially, the competition between noninertial lift force and interfacial tension drive cellular migration and therefore sorting. Breast cancer cell lines MCF-7 and MDA-MB-231 were sorted from PBMCs in the two-phase system at $>25000$ cells/min and $~ 99 \%$ sorting efficiency while maintaining viability suitable for culture. In another study, the combined effects of sheargradient lift and wall-effect lift forces were used to sort hydrogel droplets by size across fluid streamlines. Close to the inlet, randomly distributed hydrogel droplets exist in different sizes. As droplets migrate toward the outlet, they migrate to two equilibrium positions along the microchannel due to the balance of shear-gradient and wall-effect lift forces; larger droplets migrate toward the center of the channel and droplets exit outlet channels in a sizebased manner due to differences in lateral equilibrium positions. Researchers monitored the growth of microalgal cells in these droplets to passively sort empty droplets from cell-laden droplets with $93.6 \%$ purity. ${ }^{71}$

Bleilevans et al. ${ }^{72}$ combined hydrodynamic lift forces with flow focusing in a microfluidic to sort platelets from RBCs in whole blood. The sorting chip reduced $57 \%$ of baseline platelet count at a maximum flow rate of $80 \mu \mathrm{L} / \mathrm{h}$. Researchers hypothesized that microfluidic cell sorting can be a useful strategy for platelet bypassing in clinical assays in which thrombus formation must be limited. High-Reynolds inertial focusing is used to push large particles to the concave edge of curved channels due to opposing shear-induced lift forces. In microfluidic devices, this phenomenon can afford high flow rates that can eliminate clogging issues and increase throughput.

Keinan et al. ${ }^{28}$ combined this mechanism of inertial focusing with peripheral Dean vortices to isolate $10^{7}$ yeast cells $/ \mathrm{min}$ from yeast suspensions based on size differences of $1.5 \mu \mathrm{m}$. The platform provided the ability to isolate large quantities of microorganisms for proteomic and metabolomic analyses. Opposing shear-induced forces that push large particles toward the concave side of curved channels, along with superimposed effects of Dean vortices that confine small particles to the center of the channel due to rotation induced lift forces allowed for particle sorting.

Deng et al. ${ }^{73}$ developed a microfluidic device to sort living eukaryotic and bacterial cells from one another via a flow velocity gradient. This was accomplished using a low velocity sheath flow with high viscosity near the wall of the channel and a high velocity sheath flow with a low viscosity on the other side of the sample flow. This device was able to sort 1.0 and $9.9 \mu \mathrm{m}$ particles with $99 \%$ efficiency and isolate $94 \%$ of live bacteria.

Pritchard et al. ${ }^{74}$ reported a technique that utilized vortex-actuated cell sorting (VACS) to deflect individual cells by generating a temporary microfluidic inertial vortex with the aid of a thermal vapor bubble. The concept of VACS was accomplished by placing a sharp edge in a microchannel of $\sim 100 \mu \mathrm{m}$ dimension coupled with transient flow caused by microbubble expansion and collapse, which can lead to localized inertial rotation causing particle 
deflection. This mechanism can sort cells based on fluorescently labeled biomarkers with recoveries ranging from 72 to $97 \%$. Using a unique, wavy design for inertial particle focusing, Zhou et al. ${ }^{75}$ were able to focus particles as small as $3 \mu \mathrm{m}$ by producing periodically reversed Dean secondary flow along the microchannel cross sections. This sheathless microfluidic device operated at a continuous flow rate of $\sim 200 \mu \mathrm{L} / \mathrm{min}$ and utilized sharp turns (waves) that create a mismatch in lateral centrifugal forces between a continuous flow in the center and near-wall regions and through conservation of mass and generates two counter-rotating Dean vortices along the channel. The simultaneous effect of the Dean drag force and net inertial lift forces resulted in distinct equilibrium positions of differently sized cells, enabling size-based inertial sorting. The design was able to recover $\sim 90 \%$ of spiked breast cancer MCF-7 cells in a diluted blood sample with a purity between 5.3 and $69 \%$ while maintaining cell viability.

Hymel et al. ${ }^{57}$ reported on simulating the effects of cell size, cytoplasm viscoelasticity, flow rate, and bifurcation angle on sorting distance for blood cells and CTCs in bifurcating microchannels with inertial flow mechanics. The study suggested altering the bifurcation angle can increase sorting efficiency.

Vortex technology for CTC isolation is grounded on inertial microfluidics and laminar microscale vortices. ${ }^{76}$ Cells are sorted based on size and deformability on a platform typically employing a polydimethylsiloxane (PDMS) device. Lemaire et al. ${ }^{76}$ recognized in a recent publication the challenges associated with commercialization efforts of transferring technology from a research setting into the market. The authors in particular discussed the challenges of PDMS-based microfluidic chips in comparison to thermoplastics. The study compared performance metrics for CTCs isolation using PDMS and poly(methyl methacrylate), PMMA, devices. Owing to PDMS properties, significant deformation of fluidic features even under low pressure was observed (66\% vertical deformation) resulting in negatively impacted cell capture and isolation metrics. Cell sorting characteristics such as recovery, purity, and reproducibility were improved in thermoplastics. It is important to note that the authors concluded that a new material required not only optimization but may require product redesign.

\section{Deterministic Lateral Displacement and Density Gradient Centrifugation Cell Sorting.}

Flow of particles or cells in a deterministic lateral displacement (DLD) array is influenced by both the fluidic forces and created obstacles (i.e., pillars). When particles or cells are located in the gap between pillars, one with a radius smaller than the width of the streamline, will follow the initial streamline and travel in the so-called "zigzag" mode, while the particle larger than the first streamline width will be bumped by the pillar and displaced laterally to the next streamline. The cutoff size parameter between the zigzag and displacement mode is known as the DLD critical diameter $\left(D_{\mathrm{c}}\right)$. Particles smaller and larger than $D_{\mathrm{c}}$ will be sorted along the length of a DLD device.

Chien et al. ${ }^{77}$ reported modeling studies of a DLD device that employed mesoscopic hydrodynamics of RBCs in DLD devices with circular posts to better understand the interplay between cell behavior in complex microfluidic flow environments and sorting capabilities of such devices. The authors identified regimes of RBC dynamics (e.g., 
tumbling, tank-treading, and trilobe motion) and presented mode diagrams of RBC behavior (e.g., displacement, zig-zagging, and intermediate modes) while residing in the DLD device.

A two-stage device that coupled spiral inertial microfluidics and DLD was developed to sort 7 and $15 \mu \mathrm{m}$ particles with $100 \%$ efficiency. The device demonstrated $91 \%$ recovery and $18 \%$ purity when analyzing spiked tumor cells in blood. ${ }^{78}$

CTC isolation was reported by Wang et al. ${ }^{79}$ who integrated DLD microfluidic structures with magnetic-activated cell sorting to provide negative selection of WBCs. The device used diluted blood samples, operated at sample and buffer flow rates of $60 \mu \mathrm{L} / \mathrm{min}$ and $100 \mu \mathrm{L} /$ $\mathrm{min}$, respectively, and yielded a recovery of $85 \%$. Even though the device provided $57 \times$ enrichment of CTCs over WBCs, the purity of the isolated fractions was low (removal efficiency of WBCs was $98.5 \%$, meaning that in $1 \mathrm{~mL}$ of blood analyzed, there were $\sim 75$ 000 WBCs).

DLD was used for the sorting and isolation of platelet-covered CTCs in the work by Jiang et al. ${ }^{80}$ The authors considered platelets as a cell-surface marker for the isolation of plateletmasked CTCs from patient peripheral blood. The assay implemented a two-step microfluidic strategy to first deplete size-based free platelets using DLD, and in the second step, isolated $\operatorname{EpCAM}(+)$ CTCs covered by platelets using the herringbone CTC chip that was functionalized with antibodies to human platelet antigens (CD41 antibody) and EpCAM antigens. Depletion of platelets prior to CTC isolation was critical for the assay, however, even with the free platelets depleted, a low purity of isolated CTCs was observed. A significant number of WBCs were isolated on the CD41 mAb modified chip $\left(\sim 10^{5} / \mathrm{mL}\right)$, compared to the conventional EpCAM HB-chip $\left(\sim 10^{4} / \mathrm{mL}\right)$ due to the presence of plateletcovered WBCs.

Gomis et al. ${ }^{81}$ designed a DLD device to enhance cell-sorting resolution. The device implemented four DLD arrays with successively smaller critical diameters so cells can be fractioned into five distinct populations. Using multiple array regions and notched microstructures promoting cell tumbling, the device performed sorting of ciliary epithelium cells with minimal distribution overlaps between cell types. In particular, the authors characterized size distribution of retinal stem cells (RSCs), which were considered as candidates for patient-derived cell therapy to repair eye damage to determine if these cells could be distinguished from other populations of the ciliary epithelium cells based exclusively on size. While the majority of RSCs collected had diameters of $9.4 \mu \mathrm{m}$, the enrichment of this population was low $(\sim 0.5 \%)$. Cell recovery and cell viability, however, was $80 \%$, significantly higher when compared to fluorescence activated cell sorting (Figure $3 \mathrm{~A})$.

To further improve on the resolution of DLD, Xavier et al..$^{82}$ designed devices with different critical diameters for the isolation of skeletal stem cells (SSCs) from bone marrow. SSCs can be potentially used in bone regenerative therapies. Different DLD designs were evaluated for sorting based on size and rigidity of the cells as the authors discovered in their previous work that SSCs are stiffer than the three main WBC populations present in bone marrow. Designed DLDs included (i) a device that used sheath flow to hydrodynamically focus the 
sample in a narrow stream keeping cells away from the channel walls; (ii) a sheathless device, which leads to higher throughput and allowed device operation with a single input; and (iii) a device that combined the principles from the aforementioned two designs using sheath flow and a mirrored micropillar array to achieve sorting using one section of a single $D_{\mathrm{c}}$. No device provided significant enrichment due to deformation of WBCs to diameters below $D_{\mathrm{c}}$; however, the larger cells showed an increase in capacity to form clonogenic cultures indicative of stem cell potential (Figure 3B).

Strachan et al. ${ }^{83}$ developed a microfluidic device for the isolation of leukocytes based on a controlled incremental filtration (CIF) device that can operate with gravity to drive flow (Figure 3C-E). Blood cells that have an effective size greater than the threshold critical diameter of the device were retained in its central channel, whereas cells less than the cutoff size were able to be pulled into the side (i.e., filtrate channels) by the flow of fluid out of the central channel at each filtration point. The device could carry out leukaphoresis in three modes: (i) infusing blood from a syringe pump, (ii) hanging a bag containing sample 5 feet above the device, or (iii) compressing the hanging sample bag with a standard infusion cuff. The hand inflated infusion cuff that drove the sample processing delivered a flow rate of 15 $\mathrm{mL} / \mathrm{min}$; hence, a $200 \mathrm{~mL}$ leukaphoresis sample can be processed in $<15 \mathrm{~min}$. The microfluidic for the concentration of leukocytes was compared to conventional density gradient centrifugation. Paired samples showed a higher recovery of cells when the microfluidic device was used. Enriched T-cell fractions grew at a higher rate in culture than the gradient-isolated cells. Proposed benefits of the device included high-throughput, simplicity, low cost, and maintenance of sterility of the sample, which would be of great value in manufacturing CAR T-cells following isolation via cell cultures.

Sun et al ${ }^{85}$ reported a microfluidic density gradient technology that could be beneficial in research relying on mononuclear and polymorphonuclear cells isolation. The authors designed a flow-through microfluidic to provide PBMCs sorting from whole blood at lowstress conditions. A density gradient was realized by layering blood over a stream of Ficoll using laminar flow characteristics observed in microfluidics.

The work by Fachin et al. ${ }^{84}$ involved CTC isolation using DLD (Figure 3F,G). The device consisted of five microfluidic stages: DLD, first inertial focusing stage, first magnetically activated cell sorting (MACS), another inertial focusing stage, and last another MACS. DLD consisted of a monolithic chip with 128 multiplexed deterministic lateral displacement devices containing $\sim 1.5$ million microfabricated features $(12 \mu \mathrm{m}-50 \mu \mathrm{m})$ used to first deplete RBCs and platelets. The outputs from this device were serially integrated with an inertial focusing system to align nucleated cells using a shear gradient lift force, a wall interaction force, and a Dean flow to remove magnetically labeled CD45, CD16, and CD66b WBCs. Inertial focusing and MACS were repeated to provide increased efficiency of the negative selection process. Unlabeled cells (i.e., CTCs) were not affected by the MACS stages and were collected at the output. This device for antigen independent isolation achieved $99.5 \%$ recovery of CTCs, with a median of $445 \mathrm{WBCs}$ per $\mathrm{mL}$ of input blood. 


\section{Magnetic, Magnetotactic, and Magnetoresistance Cell Sorting Strategies.}

Bioanalytical systems that employ magnetic forces to isolate cells have proven useful in numerous applications. The magnetic tags, such as micro- or nanoparticles coated with antibodies, both polyclonal and monoclonal are widely available and can be easily manipulated with the aid of a magnet. A vast number of reports have utilized magnetic, magnetotactic, or magnetoresistance methods for the development of cell sorting strategies.

Yu et al. ${ }^{86}$ demonstrated a system with a magnetic separator and acoustic microfluidic focusing to enrich rare cells along with fluorescent activated cell sorting (FACS) and singlecell sequencing. This system analyzed, isolated, and sorted single cells directly into multiwell plates for molecular indexing and transcriptional profiling of single cells. The authors reported a proof-of-concept experiment with model cell lines spiked into peripheral blood that demonstrated a rapid one-step process to isolate rare cancer cells from lysed whole blood. The system provided efficient recovery of cells (92\%) compared to the 55\% recovery achieved by employing a traditional benchtop processing pipeline. Also, gene expression analysis at the single-cell level with typical cell-type dependent expression signatures for tested cell models was demonstrated.

Tay et al. ${ }^{87}$ described a magnetic microfluidic for isolation of magnetotactic bacteria (MTB) and the estimation of magnetic content in live MTBs. MTBs produce membranous structures that contain iron-rich magnetic particles enclosed within a lipid bilayer membrane. These features, called magnetosomes, have homogeneous sizes, shapes, and magnetic properties; there is interest in using MTBs as "factories" for magnetic nanoparticle production. This microfluidic platform could enrich MTBs without compromising their proliferation rate and biomineralization ability. The high-throughput format processed 25000 cells/min.

Murray et al. ${ }^{30}$ discussed an automated platform for processing rare antigen specific immune cells from blood cell samples. The method utilized a magnetic technology that employed arrays of ferromagnetically soft micropillars to isolate low-abundance immune cells that were prelabeled with magnetic beads. Using high-force magnetic ratcheting (MR), the system required no external fluidic handling system. Instead, the target cells were automatically extracted from clinical samples and processed using discrete magnetically driven displacements across the device. The MR system used an unsupervised mechatronic device that generated a cycling magnetic field capable of deterministic displacement and processing of individual cells. The authors demonstrated unsupervised collection of several immune cell types and automated postextraction culture and processing of these cells. Processing of cells at specific locations within the device, including propagation in-place, cytokine secretion analysis, nucleic acid purification, and RNA sequencing analysis was demonstrated (Figure 4A).

Molecular analysis following magnetic actuation was presented by $\mathrm{Ng}$ et al. ${ }^{17}$ This group reported a single-stream Drop-seq method called microfluidic antigen-TCR engagement sequencing (MATE-seq) for screening of barcoded nanoparticles (pNPs) against CD8+ T cells (Figure 4B). Innovations presented in this work touched on NPs providing a modular platform to streamline multiplexing by mixing combinations of primers and binding reagents on the same substrate. Also, the integration of DLD and droplet encapsulation enabled 
purified pNP-labeled $\mathrm{T}$ cells to be enclosed within droplets for nucleic acid amplification. On-chip operation included purifying the pNP-labeled $\mathrm{T}$ cells from free pNPs, entrainment of those cells into a droplet-generating microfluidic circuit, and in-droplet RT-PCR. The methodology required several advances to integrate multiple functions onto a single microfluidic chip and optimization of droplet chemistry for improved stability and efficiency during thermal cycles. The authors utilized the MATE-seq to analyze rare, virus-antigen specific CD8+ T cells.

Kokkinis et al. ${ }^{88}$ presented a microfluidic quantification platform for magnetically labeled cancer cells. The design combined isolation of magnetically tagged cancer cells from unconjugated particles utilizing giant magnetoresistance (GMR) integrated sensors (Figure 4C). The chip consisted of a channel with integrated conducting microstructures, conductors, a quantification area with GMR sensors, and storage chambers. Operations on the chip were performed under no flow conditions with the channels filled with capillary forces eliminating the need for pumps. The innovative aspect of this method was the induced velocity on the magnetic particles and magnetic particles conjugated to cancer cells. While the same magnetic field gradient was applied, it was inversely proportional to the volume of a moiety, meaning cells not associated with a magnetic tag travel faster, thus sorting themselves from those attached to cancer cells. While proof-of-concept was demonstrated with cell lines, this chip was not designed for isolating CTCs from blood in its current format.

Chen et al. ${ }^{90}$ designed a magnet-deformability hybrid integrated microfluidic chip for the enumeration of CTCs. Arrays of narrow gaps between microellipse posts were designed to capture CTCs bonded with immunomagnetic beads. The filter allowed small cells to transit through the constriction but blocked the passage of larger or less deformable cells. Multiple rows of elliptical micropillars were designed in the chip with the gap width gradually decreasing at each row. The hybrid chip delivered high capture efficiency (>90\%) even at a high flow rate.

Ghuman et al. ${ }^{20}$ described a bacteriophage-modified magnetic particle-based microfluidic device for effective isolation of target bacteria from food samples. The use of phagemodified magnetic particles in a magnetophoretic microfluidic cell sorting device allowed for highly sensitive enrichment and subsequent detection of pathogenic bacteria. Huang et al. ${ }^{91}$ designed a device to address the distribution of magnetic fields. The authors reported a microwell device for immunomagnetic single-cell trapping. The addition of a microwell layer between the microchannel and magnet produced uniform magnetic fields along the device. By introducing a "sweeping" loading protocol to expand the single-particle trapping range, process efficiency of $62 \%$ and purity of $99 \%$ was achieved. Sample processing was completed in $10 \mathrm{~min}$ and was demonstrated with cell lines.

Kye et al. ${ }^{89}$ reported a microfuidic device with dual-neodymium magnet-based negative magnetophoresis for the size-dependent sorting of microparticles and cells using nonNewtonian viscoelastic polyethylene oxide (PEO) solution and ferrofluid. PEO solution increased the viscoelasticity of the medium, which assisted in sorting microparticles in the microfuidic device at low flow rates $(7 \mu \mathrm{L} / \mathrm{min})$ (Figure 4D). 
A concept presented by Oh et al. ${ }^{24}$ used a magnetizable micropipet tip for MACS (named "MACS Tip") that enabled high-throughput and high-gradient magnetic isolation of cells via sample pipetting, which was constructed from a regular $1 \mathrm{~mL}$ pipet tip (Figure 4E). It was fabricated with layers of nickel meshes and rectangular micropores that could be transiently magnetized by placing permanent magnets in the 3D-printed frame. The large mesh surface area enabled cell enrichment by capturing magnetically tagged target cells passing through the large cross-section of the tip and allowed for releasing cells by manual pipetting and release of the magnetic field. The authors demonstrated performance of the MACS Tip by sorting bacterial cells from whole blood and their identification via PCR. Owing to this method's ability for cell isolation, washing, and release, downstream analysis could be realized.

Xu et al. ${ }^{92}$ utilized a combination of microchip-based CTC capture with multifunctional magnetic assays. It was comprised of anti-EpCAM antibodies conjugated to a $\mathrm{Fe}_{3} \mathrm{O}_{4} @ \mathrm{C}_{6} / \mathrm{Ce}_{6} @$ silane assembly and an inverted microchannel with a silicon nanowire capture surface. The assay provided fluorescence readout of enriched CTCs following capture, and a high purity of CTCs generated by the CTCs being pulled up to the capture surface, while other cells and metabolites were pulled down by gravitational forces. The authors also integrated a CTC photodynamic therapy in vitro that was realized with confocal laser scanning microscopy. The results indicated attributes of the magnetic composite labels, which greatly improved the capture purity of the CTCs to $90 \%$ and provided capture efficiency of $82 \%$ with $2 \mathrm{~mL} / \mathrm{h}$ flow rates.

Zhao et al. ${ }^{93}$ developed a CTC enrichment method based on cell magnetization in a ferrofluid. The so-called integrated ferrohydrodynamic cell separation (iFCS) merged two phenomena: (i) "diamagnetophoresis" and (ii) magnetophoresis" of cells in a biocompatible ferrofluid. Enrichment of CTCs was accomplished via antigen-independent mode and the cell size variation-inclusive method. The assay allowed for depletion of WBCs while enriching viable CTCs for clinical applications.

\section{Fluorescence-Activated Cell Sorting.}

Flow cytometry is widely used as a method for sorting cells at rates of $10^{2}-10^{5}$ events $\mathrm{s}^{-1}$. Recently, reported microfluidic designs of fluorescence-activated cell sorters (FACS) demonstrated high levels of integration to address challenges of conventional flow cytometers. Microfluidic chips can integrate components such as microchannels, optical components, and actuators to generate miniaturized systems. Cells can also be encapsulated in droplets and electrostatically deflected into collection containers depending on fluorescence in FACS.

De Wijs et al. ${ }^{94}$ reported a microvapor bubble jet flow for high-rate fluorescence-activated cell sorting (Figure 5A). The authors used a resistive metal heater to generate microvapor bubbles of reproducible volume, quantity, and lifetime. The authors demonstrated sorting of fluorescent beads at high rates and the enrichment of rare cells. Compared with other microfluidic sorting mechanisms, jet flow sorting was not dependent on any physical cell characteristic. The jet flow sorter was reported to be simple to fabricate and operate. The 
system did not contain mechanical parts and could be operated with a low power laser for bubble creation.

A spark-generated microbubble cell sorter for microfluidic flow cytometry was reported by Zhao et al. ${ }^{95}$ (Figure 5B). The advantage of this setup was realized based on a jet flow induced by a spark-generated cavitation microbubble that can be produced by a pair of electrodes. The sorter was integrated into a microfluidic chip with three-dimensional hydrodynamic focusing and a binary optical element for laser illumination. The authors demonstrated sorting with a switching time of $250 \mu$ s for a sample flow velocity of $5 \mathrm{~m} / \mathrm{s}$ and continuous operation at $200 \mathrm{~Hz}$ to deliver continuous sorting with good cell viability.

\section{Image Guided Cell Sorters.}

The integration of fluorescence microscopy and flow cytometry into a single platform provides benefits of high cell processing and analysis rates and multiparameter identification. Research on the development of image guided sorters and analyzers may provide tools for fast identification and enumeration of cells. A conventional flow cytometer will evaluate the fluorescence intensity of the objects of interest while the microscopic assessment will provide the opportunity to analyze cells based on their morphology: cell or nucleus size and shape, circularity, fluorescence pattern of stains, and volume ratio of the nucleus to cytoplasm.

Technology in cell sorting was shown based on nuclear localization of glucocorticoid receptors, particle binding to the cell membrane, and induced DNA damage. Okumus et al. ${ }^{96}$ reported a MACS platform that overcame challenges of visualization of cells in suspension by temporarily immobilizing cells within a microfluidic chip. This enabled high-throughput and automated single-cell microscopy for a wide range of cell types and sizes. MACS facilitated the visualization of individual cytoplasmic fluorescent proteins in E. coli, allowing low-abundance proteins to be counted using total internal reflection fluorescence microscopy. MACS also was used to impart mechanical pressure on cells for assessing the structural integrity of individual cells.

Isozaki et al. ${ }^{97}$ designed an intelligent image-activated cell sorter (iIACS) that delivered realtime image-based sorting of single cells with high throughput. iIACS was capable of analyzing fluorescence intensity profiles of cells and multidimensional images for sorting cells with unique morphological traits. In fact, orthogonality (i.e., the number of pixels multiplied by the number of colors) was $\sim 1000$ times greater than that by FACS (i.e., $~ 20$ colors without spatial resolution). The method was based on integration of high-throughput cell microscopy, cell focusing and sorting, and deep learning on a hybrid software-hardware data management infrastructure that enabled data acquisition, data processing, intelligent decision making, and actuation.

Nagata et al. ${ }^{98}$ designed a diffuser-type microfluidic sperm sorter (DMSS) device (Figure 5C). Manipulation of fluid flow in microchannels allowed for the isolation of undamaged, motile, mature, and physiologically functional sperm with high DNA integrity. The geometry of the microchannels consisted of three filtering zones: the crescent-shaped diffuser, multichannels, and a junction channel with precisely controlled fluid velocities that 
were relevant in inducing sperm displacements and orientation. The sperm DNA fragmentation was evaluated before and after sorting of the sperm cells. The mean frequency of spermatozoa with DNA fragmentation was $0.4 \%$ and $7.1 \%$ for DMSS-sorted and unsorted sperm, respectively, indicating that sperm selection by DMSS allows for effective recovery of not only viable and motile but also functional sperm cells with very high DNA integrity.

Spatiotemporal Image Correlation Analysis for 3D Flow Field Mapping in Microfluidic Devices to measure how flows evolve from 3D structures was established by Ceffa et al. ${ }^{99}$ The authors demonstrated the ability of mapping 3D flows in complex microchannel networks by combining wide field illumination to image correlation approaches. The work derived the spatiotemporal image correlation analysis of single-plane illumination microscopy images and developed a fitting method to measure in-plane and out-of-plane velocities.

Edwards et al. ${ }^{101}$ developed a methodology that integrated organ-on-chip-like microfluidic and photoconvertible protein technologies to investigate cancer cell dissemination processes. The authors evaluated natively expressed selectin ligands correlation with colon cancer cell rolling frequencies and velocities. They could assign a single-cell velocity as a useful cell property for further analysis of cell molecular profiles and adhesive phenotypes.

Gu et al. ${ }^{102}$ demonstrated an image-guided cell sorting and classification system possessing a throughput comparable to conventional flow cytometry with the high information content of microscopy. The utility of this technology in cell sorting was shown based on nuclear localization of glucocorticoid receptors, particle binding to the cell membrane, and induced DNA damage.

\section{Optofluidic Cell Sorting.}

An image-activated cell sorter that integrated cell microscopy, cell focusing, and cell sorting on a hybrid software-hardware data-management infrastructure enabled real-time automated operation for data acquisition, processing, identification, and actuation. Nitta et al. ${ }^{103}$ presented this so-called optical-microfluidic-electrical-computational-mechanical system demonstrating high flexibility and scalability, automated operation for data acquisition and processing, and importantly decision-making and actuation all within $32 \mathrm{~ms}$ even for deeplearning algorithms.

Yu et al. ${ }^{29}$ reported an automated system for the identification of cells with morphological features using optical imaging and a designed classification algorithm. A microfluidic device provided a customizable platform for cell sorting based on image processing. On-chip valves and pumps allowed for cell isolation and shuttling to an observation window for confirmatory analysis. The system was designed to operate in two modes: the forward sorting mode, where the sample passed through a flow-focusing unit and, with the aid of sheath flow, cells could pass aligned through the cell identification region. If a cell was classified, the valves in the two sorting channels direct cells to a collection or waste reservoir. In the second mode, called a reverse identification mode, the cells stored in the chamber were pushed back toward a reverse waste reservoir and passed through the 
identification area that looked for the presence of fluorescence markers. The automated device delivered low-cost image processing and cell sorting.

Work by Hamza et al. ${ }^{104}$ addressed challenges related to low blood volume samples available for CTC testing in longitudinal studies in animal models. They developed an optofluidic system (Figure 6D) capable of identification of fluorescent CTCs and their direction to a collection well for analysis. Cancer cells in this mouse model produced fluorescence, including CTCs. The analysis system included a microfluidic CTC sorter chip, a fluorescence detector, and computer-controlled pneumatics. This CTC chip was connected to the mouse via left carotid artery and the output blood from the chip was infused back into the mouse through the right jugular vein at a rate of $30 \mu \mathrm{L} / \mathrm{min}$. Two closely spaced laser beamlines illuminated the main flow channel of the chip to monitor CTC abundance and perform sorting. Each fluorescent cell that passed through the device emitted two pulses of light, which were detected by a PMT. The controller operated pneumatic valves to redirect a small blood volume with the CTCs toward a collection tube. CTCs in blood from the collection tube were further enriched by a secondary single-CTC sorting chip and further analyzed. The authors used scRNA-Seq to show that continuous CTC capture from the same murine animal eliminated bias driven by interanimal heterogeneity that occurred when CTCs were collected across different mice.

Hu et al. ${ }^{105}$ used optofluidics for the isolation of CTCs based on their interactions with RBCs via folate receptors. Complexes of cancer cells with RBCs were sorted under laser illumination in an optofluidic system with $92 \%$ purity and $>90 \%$ recovery. The combination of RBC binding and an optofluidic system provided a potential tool for early detection of cancer.

Another application of optofluidics was demonstrated by Landry et al. ${ }^{23}$ who developed a method for single-cell genome amplification from sorted via an optical trap bacterioplankton cells. The device retrieved diverse single-cell bacterioplankton genomes and offered utility in microbiology applications that required working with small sample volumes.

Lee et al. ${ }^{16}$ described the optimization of a Raman-activated cell-sorting system. This optofluidic platform performed automated sorting of isotopically labeled microbial cells and combined microfluidics, optical tweezers, and Raman spectroscopy to achieve sorting of live cells as verified by cell culture. The sample enrichment and preconcentration was needed for single-bacterial cell genomic analysis. Design testing with bacterial cells showed $98 \%$ sorting efficiency with a throughput of 500 cells/h. Liu et al. ${ }^{106}$ developed an optofluidic platform for bacterial cell sorting. Fiber tweezers were integrated into a microfluidic channel to build a chip that trapped bacterial cells based on size and shape. E. coli trapping from blood was empirically evaluated and compared with simulations for the trapping of different shapes of cells, including bacterial and mammalian cells. The advantages of the system included low optical power and compact construction, all important for potential field testing.

Tkachenko et al. ${ }^{107}$ reported an optical device for trapping of micrometer sized objects using planar silicon metalenses illuminated with a collimated laser beam. The metalenses in the 
system consisted of high-contrast gratings with a varying period and duty cycle and parabolic reflectors. Both, two- and three-dimensional trapping in water was demonstrated. Lithographically made metastructures for sorting with optical forces replaced the need for bulky optical elements. Design of the focusing optics in a planar format was attractive and conducive to the integration of microscale devices.

\section{Droplet Cell Sorting.}

Due to the similarities in volume between droplets and cells, a droplet represents a selfcontained sample vessel or microreactor for a single cell, allowing for parallel studies and high-throughput analysis. ${ }^{108}$ Formation of droplets in microfluidics provides the advantage of creating a monodisperse population of droplets. Sorting of droplets requires the ability to discriminate their properties when biologicals are contained within them. To achieve this, different phenomena have been used to classify droplets based on their content.

Discrimination can be accomplished based on droplet size, electrical, magnetic, or optical properties. $^{109}$

Jyoti Dipanka Shaikeea et al. ${ }^{110}$ utilized a process of a naturally evaporating colloidal sessile droplet interacting with a porous silica gel bead to mimic a so-called mechanical crane assembly. This particular mechanism involved self-assembly along a droplet-bead interface and bonding. The evaporating droplets automatically lift the bead. These observations across multiple spatiotemporal scales provided insights into the design of droplet engineering.

Turk-MacLeod et al. ${ }^{111}$ proposed to sort objects in an ensemble rather than as discrete objects. A set of so-called registers were sorted and then sorted again into a second symmetric set of registers without loss. The process was repeated resulting in high sorting purity. The system was modeled and tested on objects spanning several orders of scale, from macroscopic beads to micrometer sized droplets.

Yu et al. ${ }^{112}$ reported an on-chip encapsulation and analysis of protoplasts at processing rates of $>100000$ cells $/ \mathrm{h}$. The work demonstrated the ability to dielectrophoretically sort droplets containing fluorescing protoplasts from nonfluorescent control cells. A microfluidic system was used for quantification of the stochastic properties of a heat-induced promoter in a population of transgenic protoplasts and to demonstrate the ability to evaluate gene expression modulation in response to environmental conditions.

Pan et al. ${ }^{113}$ presented a droplet microfluidic for label-free and passive selection of live cells. The method, named sorting by interfacial tension (SIFT), discussed an interesting new strategy to sort viable cells. The selection and sorting of droplets was based on metabolic activity of individual cells and interfacial tension of droplets. Release of lactate by viable cells resulted in a $\mathrm{pH}$ decrease, which changed the interfacial tension of droplets when a particular surfactant was used for droplet preparation.

Fluorescence-based droplet sorting was employed by Shembekar et al. ${ }^{114}$ The authors presented a high-throughput droplet microfluidics approach employing dual-color normalized fluorescence readout to detect antibody binding. The assay allowed collection of quantitative data related to cell antigen recognition using minute amounts of antibody. 
Specific binders of target cells coencapsulated into droplets enriched 220-fold following sorting of 80000 clones. This droplet-based assay would allow for therapeutic antibody discovery using primary human plasma cells.

Qin et al. ${ }^{122}$ discussed work on a fluorescence-activated single-droplet dispenser (FASD), that used cytometric detection and electrohydrodynamic actuation-based single-droplet manipulation. FASD allowed for droplet isolation and dispensing with high efficiency and accuracy. Droplets could be collected into conventional multiwell plates or secondary largescale screening systems.

Buryk-Iggers et al. ${ }^{123}$ demonstrated a diamagnetic droplet microfluidic method in which cell-encapsulating droplets were precisely controlled based on magnetophoresis, a phenomenon where particles migrate in a magnetic field. The droplet phase was comprised of cells suspended in culture medium, and the magnetic content was contained in the continuous phase. Encapsulated cells produce larger droplets when compared to empty ones. By the application of a magnetic field, diamagnetic size-based sorting of empty droplets from cell-encapsulated droplets was achieved. The same research group explored a similar concept ${ }^{115}$ and demonstrated the integration of ferrofluids in a polymeric aqueous two-phase system to achieve diamagnetically responsive water-in-water droplets (Figure 6A).

Li et al. ${ }^{116}$ presented work on the acoustophoretic system for fluorescence-activated sorting at the single-droplet level (Figure 6B). The fluorescence-activated droplet sorting technique acted along with focused traveling surface acoustic beam of $\sim 50 \mu \mathrm{m}$ with a resonance frequency of $98 \mathrm{MHz}$. When an individual droplet containing fluorescently labeled cells passed through the laser spot (i.e., fluorescence interrogation region), the fluorescent label was excited and the emitted light transmitted to a PMT that converted the received light intensity into an electrical signal. Each high-level electrical pulse signal from the PMT triggered a radio frequency (rf) generator to produce a pulsed ac signal. The ac signal after power amplification was applied to a FIDTs to generate a focused traveling surface acoustic wave (FTSAW) beam resulting from the piezoelectric effect. When the FTSAW traveled along the surface of the FIDT device and encountered a micropillar, it radiated into the micropillar that acted as a waveguide to locally transmit the FTSAW into the sorting region. A frequency of $\sim 1 \mathrm{kHz}$ delivered $90 \%$ purity of sorted events. The detachable acoustic droplet sorting system allowed the reusability of the costly FIDT device and avoided sample cross-contamination by adopting a single-use microfluidic channel device.

Kim et al. ${ }^{117}$ also described a droplet-based system for single-cell reverse transcription polymerase chain reaction (RT-PCR) (Figure 6C). The device combined biological cells with lysing buffer using droplet generation and mixing of these droplets in a microfluidic Tjunction with larger volume droplets containing enzymes and reagents for RT-PCR.

Schaerli et al. ${ }^{26}$ demonstrated a microfluidic method for high-throughput screening of bacterial cells in gel-based emulsion beads. Beads were incubated allowing for fluorescently tagged cells to grow into monoclonal colonies inside the beads. By identification based on fluorescence, very specific colonies were selected by FACS. Following FACS, the bacteria were recovered from the gel beads and ready for further analysis. 
Zhu et al. ${ }^{124}$ reported quantitative proteomic analysis of single mammalian cells utilizing a nanodroplet sample processing chip along with ultrasensitive nanoLC-MS. The system was demonstrated with model cell lines with identification of even a single cell due to high-level proteome coverage.

Utharala et al. ${ }^{125}$ described a microfluidic platform for partitioning and sorting particles including molecules, cells, and embryos. The system was attached to a fluorescence microscope. The platform contained valves used for opening and closing microfluidic channels to enable sorting rates $>2 \mathrm{~Hz}$. The microfluidic also performed 8-way sorting, simplifying the simultaneous enrichment of objects based on their particular characteristics or phenotype.

Chung et al. ${ }^{118}$ reported a microfluidic system that coupled continuous-flow dropletgeneration and sorting with droplet merging allowing for addition of reactants or biologicals to the droplets (Figure 6D). The platform included multiple steps for manipulation of droplets. The process began with the generation of $125 \mu \mathrm{m}$ large droplets containing, for example, enzymes, primers, or the appropriate buffer. In order to add reactants or cells to this droplet, smaller droplets were generated $(\sim 6 \mu \mathrm{m})$ containing both cells and lysing buffer. Cells and lysis buffer do not mix before coencapsulation in a droplet, so lysis occurred only in the droplet. A fluorescence-activated droplet sorter selected droplets that contained cellular material based on fluorescence coming from the nuclear DNA. Merging of small and large paired droplets was executed by applying high voltage electric fields that induced dielectric forces. The system was successfully tested for single-cell reverse transcription loop-mediated-isothermal amplification to quantify mRNA expression levels.

Segaliny et al. ${ }^{119}$ used droplet microfluidics for screening and real-time monitoring of the activation of $\mathrm{T}$ cells expressing an engineered $\mathrm{T}$ cell receptor (TCR) following the recognition of tumor cells (Figure 6E). The idea behind this work stemmed from a need of identifying candidate $\mathrm{T}$ cell therapeutics for cancer treatments and the requisite for understanding their TCR sequence. The authors demonstrated visualization of the dynamics of TCR T cell interactions with target cells, measured the activation kinetics, sorted TCR T clones using laser-based cavitation, and performed downstream molecular analysis using single cell RT-PCR and sequencing.

Ahmadi et al. ${ }^{120}$ presented an integrated digital-droplet microfluidic that combined the use of single-plate digital microfluidic chip and droplet-in-channel microfluidics (Figure 6F). The system featured on-demand mixing of droplets and facilitated creation of different concentrations with multiple additions using an electric potential without the need for optimizing flow rates. Overall, the following stages were included within the system: droplet generation by a flow-focusing or T-junction configuration, droplet mixing, incubation, detection, and sorting. The authors also incorporated traps allowing for droplets to be incubated for extended periods of time. Application of this microfluidic device to the study of the effect of an ionic liquid on yeast cells was demonstrated.

Li et al. ${ }^{121}$ designed an array-based emulsification method for the generation of monodisperse agarose-in-oil droplets for application in single copy DNA amplification in a 
microwell array (Figure 6G). Agarose monodispersed and size-tunable droplets were formed when hot oil was introduced into an agarose solution contained in wells. The droplet size formed depended on the array unit depth and width. More than 100000 uniform droplets were generated in less than 1 min using a preformed agarose well array. A single-copy of DNA was efficiently amplified in picoliter droplets, enabling accurate absolute quantitation of DNA molecules.

\section{Hybrid-Based Methods Employing Cell Separation and Sorting.}

Cells of various types and function may often differ in size, stiffness, and/or deformation response. A number of physiological states can alter these cellular characteristics, and therefore sorting/separation technologies aimed at exploiting these traits can be useful in a variety of settings. The aforementioned cellular characteristics can be used to separate and/or sort cells either in discrete devices or in combination on a single device.

\section{Size and Elasticity Cell Separations and Sorting.}

The effects of circular, irregular, and rectangular microchannel cross sections on the forces that act upon normal and stiffened RBCs were studied by Chen et al., ${ }^{126}$ who performed flow simulations to analyze distribution effects on cell movement in geometrically different microchannels. Additionally, migration velocities of RBCs in viscoelastic solutions were deduced. A microfluidic device developed by Yuan et al. ${ }^{127}$ coupled the effects of fluid elasticity, inertial, and Dean-flow forces to accelerate particle focusing in a serpentine microchannel by adding elasticity-altering polymers to the sample.

Du et al. ${ }^{128}$ demonstrated that applied stress in the form of atomic force microscopy (AFM) can be used to precisely identify mechanical distinctions in different stem cell populations in regards to deformability and rupture response; AFM-induced stress could potentially be utilized as a label-free marker in microfluidic systems. A microfluidic device utilized periodic diagonal ridges to sort drug-resistant and leukemia cells by differences in stiffness after treatment with chemotherapy in a label-free manner, achieving up to 93\% purity. Sorted cells were tested for their gene expression and AFM was used to validate that sorting was accomplished via stiffness. Islam et al. ${ }^{129}$ used a ridged-microfluidic device to sort drug-resistant and sensitive leukemia cells by differences in stiffness after chemotherapy. Their experimental results were validated by AFM analysis.

Bongiorno et al. ${ }^{130}$ utilized AFM to evaluate biomechanical properties of cells. Based on their findings, the authors employed a microfluidic device for the enrichment of pluripotent cells based on their characteristic stiffness. The device was employed to sort a differentially labeled mixture of pluripotent and differentiating cells, resulting in pluripotent cell enrichment. These properties were verified via phenotyping, postsorting characterization of cell mechanics, morphology, and gene expression. Findings from the aforementioned publication suggested that cell mechanical properties may serve as a metric for a label-free isolation of stem cells to facilitate study of pluripotency and advance the field of tissue engineering and regenerative medicine in the future.

Girardo et al. ${ }^{131}$ demonstrated high-throughput production of elastic microgel beads that mimic cell elastic properties. Beads were employed as calibration standards for different 
mechanical techniques for studying cell biomechanics. The authors presented methods for functionalization of beads to further applications in cells and organoids for tissue mechanical characterization. These beads could serve as useful models in cell cultures, for example, to study the effect of stress acting on nuclei during cell division.

A wedge-shaped microfluidic device made from two glass slides was able to separate spiked CTCs in blood with $~ 90 \%$ efficiency. The device was composed of a wedge-shaped microchamber, two inlets, a linear reservoir, and one outlet. The microchamber was the principal component of the chip, and Yang et al. ${ }^{132}$ evaluated the effect of size-cutoffs for CTCs on capture efficiencies by altering the chamber outlet height. Due to biophysical differences of size, stiffness, and deformability between CTCs and RBCs, CTCs were separated from RBCs efficiently in microchambers when the cutoff height was larger than that of RBCs but smaller than most of the CTCs. RBCs freely flowed through the chamber whereas CTCs were physically trapped (i.e., separated). The unique wedge shape allowed for a size-cutoff of $5 \mu \mathrm{m}$ to entrap CTCs from blood. The device was also able to incorporate high-resolution fluorescence imaging (Figure 7A).

A multilayered microfluidic device that achieved filtration via a nylon mesh was recently developed to achieve separation of tissue fragments, cell aggregates, and single cells from digested murine kidney and mammary tumor tissue samples. Two microporous membranes worked together to accomplish filtration, with the first membrane poised to restrict large tissue fragments and the second membrane to restrict smaller aggregates from reaching the outlet (Figure 7B). ${ }^{133}$ The device was designed to operate in either a traditional direct filtration mode, or a tangential filtration mode that utilized a cross-flow to prevent membrane clogging. Qiu et al. presented the ability to separate up to $85 \%$ of cell aggregates and clusters in just $15 \mathrm{~min}$, yielding comparable results to a full $60 \mathrm{~min}$ traditional tissue digestion.

Ren et al. ${ }^{134}$ fabricated microgel beads to be used as an elasticity comparison for the classification of cancer cells from normal cells. They demonstrated a microfluidic that exploited confining capture chambers capable of achieving classification rates $>75 \%$ when exposed to whole blood containing breast cancer cell lines. Microgel beads were mixed with cell samples, and penetration differences seen by captured cells in the confining chambers afforded differentiation between beads and normal or cancerous cells (Figure 7C).

A lattice-patterned microfluidic device accomplished size-based enrichment of 3 and $10 \mu \mathrm{m}$ particles using dual-depth asymmetrical microchannel networks. The device utilized threedimensional (3D) hydrodynamic flows to accomplish separation of various sized particles. The dual-depth lattices enabled Yanai et al. ${ }^{135}$ to create an anisotropic flow distribution at microchannel crossing points. Main channels were slanted, whereas the perpendicular separation channels were shallower. Observations of these channels revealed complex 3D flows that dominated size-dependent differences in particle behaviors (Figure 7D).

A pump-free single layer microarray fabricated in PDMS was developed for the trapping of single cells using cell membrane permeability as a mode for cell separation (Figure 7E). The device featured an array of $\sim 77$ symmetrical butterfly shaped traps functioning as a trapping- 
DLD hybrid, which deflected particles larger than the critical size, while also enabled trapping of particles with a diameter smaller than $D_{\mathrm{c}}$ but larger than the aperture width. Microspheres (18.8 $\mu \mathrm{m}$ diameter) were used as a model and were trapped via deterministic lateral displacement with $86.8 \%$ occupancy. Weng et al. ${ }^{136}$ utilized the device to determine the membrane permeability of rat hepatocytes and CTCs.

Hydrodynamic filtration (HDF) was utilized to achieve size-based sorting of particles and blood cells at a particle sorting throughput of $15 \mathrm{~mL} / \mathrm{min}$ using a recently developed stackable microfluidic device (Figure 7F). HDF utilized a continuous laminar fluid flow that was introduced in the left-to-right direction in a straight channel with perpendicular branched cross sections. When the relative flow rates to the side channels were low with respect to the main channel, only a small portion of liquid was directed into the side channels, making it impossible for particles to enter the branches. By increasing flow rates into the side channels, aligned particles could be collected according to size. By taking advantage of this phenomenon, the device was able to achieve $~ 4000$-fold enrichment of WBCs from a diluted blood sample. ${ }^{137}$

Mehendale et al. ${ }^{138}$ combined the advantages of dead-end and cross-flow filters in a separation device called the Radial Pillar Device (RAPID), which was able to sort large and small rare particles from a mixed population without clogging at a flow rate of $3 \mathrm{~mL} / \mathrm{min}$. From a mixture containing 2, 7, and $10 \mu \mathrm{m}$ particles, the device sorted 2 and $10 \mu \mathrm{m}$ particles with $90 \%$ purity and recovery.

Kamyabi et al. ${ }^{139}$ were able to isolate CTC clusters from $1 \mathrm{~mL}$ of whole blood in under an hour by using a microfluidic device equipped with 10000 trap chambers. Cluster separation was accomplished based on size and dynamic force balanced against a flow-bifurcatingpillar within the trap chambers. Capture and release efficiencies of $66-87 \%$ and $76-90 \%$, respectively, were observed using this device.

The Parsortix cell separation system was developed to capture and separate rare cells from blood based on cell size and deformability. Harvested cells from the system were successfully assessed via cytological methods including fluorescence in situ hybridization (FISH). The system demonstrated $81 \%$ capture and $74 \%$ harvest rate. ${ }^{140}$

Wang et al. ${ }^{141}$ developed a microchip for sized-based single-cell isolation. The chip contained several isolation units consisting of trap, bypass, and release channels. Larger tumor cells were preferentially confined in the trapping channel due to low flow resistance. Once a cell was confined, the flow resistance increased significantly and cells flowed through the bypass channel warranting single-cell entrapment. Bypass channels were designed with a width to allow passage of a single row of cells. Captured cells were released with a microvalving system redirecting flow, affording both, the recovery and purity of CTC models of $\sim 93 \%$.

\section{Dielectrophoretic Cell Separations and Sorting.}

Dielectrophoresis (DEP) utilizes nonuniform inductions and attractions of displaced charges within particles or cells to affect sorting or separation processes. ${ }^{142}$ Externally applied 
alternating (ac) or direct current (dc) can enable the separation or sorting of cells due to differences in cell polarizability. DEP is able to manipulate and separate cells without the need for biochemical labels or other tags and without contact to any surface. ${ }^{143}$ While most of these devices trap cells near a particular electrode due to the cell's unique electrical properties, in some cases DEP devices can be operated in a cell sorting mode of operation as well.

Puri et al. ${ }^{144}$ performed a comparative analysis of yeast cell sorting efficiency using gold and carbon electrode DEP devices. In this work, the authors emphasized that carbon electrodes could function as a durable low-cost alternative to noble metal electrodes.

Adams et al. ${ }^{145}$ published work demonstrating three different DEP-based devices for the separation and sorting of neural stem and progenitor cells. These devices included a DEP microwell, an automated DEP with 6000 cells/h throughput and a large capacity electrode array (LCEA) capable of 150000 cells/h throughput. The DEP microwell device consisted of a $3 \times 5$ microwell array fabricated in PDMS with gold electrodes at the bottom of each well. Specific cells were separated along the electrode edges and cells that did not experience positive DEP (pDEP) remained in suspension above the electrodes. A wash buffer removed nontrapped cells while the electric field was still on, and this process was repeated until a sufficient number of cells were collected. The automated DEP device had microfluidic channels with three castellated electrode regions for cell trapping and an additional array for cell screening. One main microfluidic channel branched off to five different channels for collection. Fluid flow was controlled by a valving system. Once cells were trapped, fluid flow was stopped and the applied electric field frequency reduced, which released a subset of cells. The released cells were directed to collection outlets by opening valves while the reduced frequency was maintained. The LCEA included planar interdigitated electrodes with two inlets and one outlet. Once cells reached the electrode region, the electric field was turned on and viable cells experienced pDEP and were retained. Cells were then released by lowering the frequency incrementally and collected at an outlet port.

Schucat et al. ${ }^{146}$ designed an electrode array in a microfluidic device to act as an automated platform for sperm cell separation. A quadrupolar electrode array was fabricated onto an indium tin oxide (ITO)-coated glass slide using photolithography and wet-etching and a PDMS microchannel was utilized to examine the effects of different DEP forces on sperm cells. The study observed that the head and tail of the spermatozoa exhibited independent DEP behavior, either pDEP or negative DEP (nDEP) at a particular frequency. The tail of the sperm cells switched from a nDEP response to a pDEP response at low frequency. There was a range of frequencies where the sperm head underwent nDEP while the tail underwent pDEP providing proof-of-concept that DEP has the potential to automate and improve semen sample separation without damaging the cells. For a prototypical chip, researchers fabricated a pair of curved electrodes to which the sperm tail was attracted and the head repelled, resulting in perpendicular sperm cell alignment. Depending on electrode design, the researchers concluded that pDEP can be safely used as a mechanism to separate sperm cells from debris. 
Coupling DEP and Raman spectroscopy, Hanson et al. ${ }^{21}$ were able to successfully isolate a mixed sample of bacteria and $3 \mu \mathrm{m}$ polystyrene particles from each other. The device consisted of two pillar arrays for debris removal and bacterial trapping for label-free Raman spectral analysis, enabling 100\% classification accuracy among closely related bacteria.

By combining DEP and hydrodynamic drag forces, Xing et al. ${ }^{147}$ fabricated a microfluidic device for continuous-flow cell sorting (Figure 8A,B). Silicon microelectrodes acted as physical tracks that rail cells away from incoming streams of fluid. For cell sorting, a stream of cells was introduced and flanked by a sheath flow into the flow chamber toward the side that was in support of the cell railing. Uninterrupted flow was ensured by passages beneath the railing tracks. Nontargeted cells experienced nDEP and reached the primary outlet, whereas target cells experienced pDEP and were railed along the tracks. The device was able to sort a binary mixture of different cancer cell lines with collection efficiencies $>85 \%$ at a sample flow rate of $0.5 \mathrm{~mL} / \mathrm{h}$. Another microfluidic device that coupled both DEP and hydrodynamic forces was able to isolate lung cancer cells from RBCs at a sorting efficiency of $91.7 \%$ for RBCs and $100 \%$ for cancer cells. DEP was accomplished by 3D sidewall electrodes, and the hydrodynamic unit was composed of contraction and expansion microchannels to increase the electric field gradient, hence, enhancing DEP forces imposed on the cells. These enhanced forces acted as an additional shear gradient lift force to induce secondary flow. ${ }^{149}$

A microfluidic device by Wu et al. ${ }^{148}$ utilized actuation and bipolar electrodes in DEP to accomplish multiple functions: cell sorting, single-cell trapping, and cell manipulation (Figure 8C). Actuation electrodes were patterned on the bottom of the device and deflected cells into a buffer stream due to strong nDEP forces. Bipolar electrodes consisted of electronic conductors in contact with an ionically conductive medium in which a linear potential gradient was generated between the ionic solution and the electrodes by applying a voltage between the driving electrodes. In this device, each bipolar electrode floated to an equilibrium potential controlled by the solution potential gradient, which allowed for single cell trapping, rotation, and propulsion. Single cells were trapped and manipulated by altering the distribution of an ac electric field via these bipolar electrodes. Yeast cells were sorted from polystyrene microbeads with $>90 \%$ efficiency, and single yeast cells could be trapped with $72 \%$ efficiency. Additionally, yeast cells were oriented and steered around the device at a speed of $94.2 \mu \mathrm{m} / \mathrm{min}$ by using DEP at the bipolar electrodes. ${ }^{148}$

Single-particle manipulation by optically induced dielectrophoresis (ODEP) was first described by Chiou et al. ${ }^{150}$ Indium tin oxide glass and a layered photoconductive surface were necessary to achieve ODEP. When projected light hits the photoconductive layer, virtual electrodes were turned on to create nonuniform electric fields, which allowed cell manipulation. This photoconductive layer could be applied in specific patterns and cells could be either attracted or repelled by an illuminated area depending on the ac frequency generated and the dielectric properties of the cell. ODEP has seen usage in the realm of cell sorting and separation. Chiu et al. ${ }^{151}$ took advantage of this in a study for the isolation of CTC clusters from blood, affording cell purity and recovery of 91.5 and $70.5 \%$, respectively. The device used a dynamic square light image array for continuous cell isolation from background WBCs based on significant size differences; the clusters were diverted to a side 
microchannel for further purification. Additionally, ODEP has been used with fluorescence microscopy in a microfluidic device to achieve isolation of live CD45(-)/EpCAM(-) cells from blood samples with purity $\sim 100 \% .{ }^{152}$

Thomas et al. ${ }^{153}$ described a system in which a "virtual channel" generated by negative dielectrophoresis is utilized for cell sorting. This virtual channel runs along the center of the microfluidic channel and automatically directed cells along a specific path by switching the polarity of the electrodes; the system interpreted video data and sorted it based on color, intensity, size, and shape. Researchers were able to sort osteosarcoma and human bone marrow cells with $74 \%$ recovery at a flow rate of $60 \mathrm{~nL} / \mathrm{min}$.

\section{Impedance Cytometers: Label-Free Counting of Enriched Cells.}

Impedance measurements of biological cells is a label-free, noninvasive, and quantitative analytical method. Impedance sensing is based on measuring the impedance from a frequency-dependent voltage signal (i.e., excitation signal) applied to the target. Impedance measurements provide the opportunity for high-throughput analysis of cells and particles, which is convenient when a large number of particles or cells need to be characterized and counted. Solsona et al. ${ }^{154}$ addressed challenges related to the detection of the exact position of cells or particles as they enter the sensing zone between the electrodes when impedance data are collected. Using platinum electrodes fabricated as an array with a gradually increasing surface area, the authors demonstrated that an electric field gradient in a parallel two electrode array allowed for tracking of particle position in one axis. By using low frequency measurements, it was possible to detect the exact position of the particles. At higher frequencies, where the impedance of the medium dominates and the current density is homogeneous throughout the entire electrochemical cell, the conductivity of particles or cells can be measured. Studies used a finite element model to define the frequency range at which both the position and conductivity of the particles or cells can be detected and measured. The model was validated with microparticles using a microfluidic chip with linearly increasing electrodeposited areas perpendicular to the flow direction.

Petchakup et al. ${ }^{155}$ reported on leukocytes sorted from blood using a Dean flow fractionation device and follow-up impedance profiling of sorted cells (Figure 9A,B). The detector consisted of a three-electrode setup; the middle electrode was supplied with potential at two different frequencies and the differential current response from cells was recorded from the side electrodes and sent to a lock-in amplifier to extract a magnitude and phase of the signal of interest. In this application, a microfluidic impedance flow cytometer was used for testing and characterizing neutrophils and monocytes obtained from patients with type 2 diabetes. Here, leukocyte dielectric properties were associated with cardiovascular risk factors. Additionally, tested cells demonstrated pro-inflammatory phenotypes, which would imply that leukocyte impedance signatures could be used as a biomarker of inflammation. The method was also able to monitor monocyte differentiation and provide biophysical characterization of monocyte subsets.

Yang et al., ${ }^{156}$ similar to the work of Solsona et al., ${ }^{154}$ demonstrated an impedance sensor consisting of a three electrode detector with an $\mathrm{N}$-shaped design. The microfluidic impedance flow cytometer was designed in that way to provide information on the lateral 
position of measured cells and particles. A differential current collected from the $\mathrm{N}$-shaped electrodes encoded the trajectory of flowing single particles (Figure 9C).

Research results presented by Honrado et al. ${ }^{33}$ evaluated changes in biophysical properties of RBCs during the malaria infection cycle using an impedance sensor (Figure 9D). Microfluidic impedance cytometry measured the dielectric properties of Plasmodium falciparum-infected RBCs, and the results demonstrated that the membrane capacitance and cytoplasmic conductivity of infected RBCs increased during the time course of the infection, possibly correlating with the increasing volume occupied by the parasite. The authors suggested that their findings could be used for the development of DEP-based sorting of RBCs as a standard parasite detection protocol during post ring-stage of the infection cycle with increasing sensitivity over current diagnostic methods. The cell or particle lateral position was derived from the measured electrical signal and distance relationship between the positions of particles, electrodes, and microchannels. The results demonstrated that the device could measure the lateral position of single particles and cells while simultaneously characterizing their size.

\section{Integrated Systems for Cell Analysis.}

Li et al. ${ }^{157}$ demonstrated and validated in clinical work an integrated system for processing blood samples and whole genome amplification (WGA) of gDNA isolated from CTCs (Figure 10A). All steps, including blood filtering, CTC enrichment, identification, isolation, lysis, and WGA were performed on a single device. The authors established a so-called "whole blood in, WGA product out" concept by incorporating multiple analysis steps for analysis at the single-cell level. The integrated chip incorporated novel tristate valves that could perform the role of a valve and an active mixer to ensure successful single cell WGA.

Zhang et al. ${ }^{158}$ reported an integrated system that used a disposable microfluidic device and a fluid control system for label-free automated cell separation (Figure 10B). The instrument consisted of the following components: a flow inlet chip for sample and sheath streams, a flow regulatory chip for flow rate regulation, two cell separation chips, and a flow outlet chip for waste and product collection. Chips were fabricated with four layers of adhesives. The sample and sheath fluids were infused into the flow inlet chip under pressurized gas and flow was regulated by another so-called regulatory chip with passive microvalves. Cell labelfree sorting was accomplished by Dean-flow fractionation (DFF). The chip design included spiral channels patterned in parallel, with each spiral channel maintaining two inlets and two outlets. In the spiral channel, sample and sheath were introduced into the outer and inner inlets, respectively. Model cell lines were isolated from blood with a recovery of $\sim 85 \%$ within $20 \mathrm{~min}$. The instrument provided rapid cell processing.

Tian et al. ${ }^{14}$ designed a microfluidic with $1.5 \mu \mathrm{m}$ posts spaced $2 \mu \mathrm{m}$ apart to arrest cells on a micropillar array (Figure 10C). The device provided means to trap a single cell and lyse it on-chip with the released gDNA being entangled on the micropillars owing to its length. Following gDNA isolation, WGA via micropillar arrays (GAMA) was performed. The gDNA amplified by GAMA had a higher percentage of mapped reads compared to single cells isolated through FACS and amplified by conventional assays. Benefits of GAMA were attributed to the WGA at a constant hydrodynamic flow, allowing for reagent replenishment 
and removal of amplified products. As a result of the GAMA purification of gDNA (i.e., removal of lipids, proteins, RNA, and mDNA), a smaller number of artifacts were found in the amplification products.

An image-based cell isolation technology, DEPArray, combined microelectronics and microfluidics in an automated and integrated platform. The device was able to isolate highly pure, single, and viable cells from a heterogeneous sample. The device demonstrated $100 \%$ purity of isolated tumor cells from WBCs across multiple devices. ${ }^{159}$

An integrated cell sorting system, called On-chip Sort, included a disposable microfluidic device that afforded immunophenotype-based detection of CTCs from pretreated blood (removal of RBCs and WBCs). The device enabled the detection of $\operatorname{EpCAM(-)~cells~when~}$ using an EMT marker conjugated to magnetic beads. When CTC counts for paired samples were compared with those isolated on an FDA approved CellSearch platform, On-chip Sort delivered higher clinical sensitivities. The device also enabled the molecular characterization of CTCs using droplet digital PCR. ${ }^{160}$

\section{FUTURE OUTLOOK}

Separating and sorting target cells from mixed populations is the first step in the cellular analysis pathway. As demonstrated in this review, biomolecular analysis can provide additional multivariate information (i.e., viability, phenotype, DNA mutational status, mRNA expression, etc.). For example, in the field of CTC inquiry, downstream molecular analysis is required to provide supporting information, as CTC enumeration alone may not be adequate in terms of enabling decisions on the management of various diseases. ${ }^{161}$ Indeed, the decisions in the area of precision medicine are based on the molecular composition of a patient's disease. In spite of the high analytical figures-of-merit (i.e., recovery and purity) associated with many of the techniques outlined in this review, biology may intrinsically limit the number of enriched cells available for molecular profiling as well as the purity of the enriched cellular fraction. For example, CTCs abundance is highly dependent on the stage and type of the disease and the treatment regimen of the patient. 162,163

There are a number of benchtop techniques to analyze nucleic acids or proteins contained within enriched cells. In the case of nucleic acids, when dealing with low copy numbers harvested from enriched cells, polymerase chain reaction (PCR) technologies continue to be the major starting point for molecular profiling because they can provide high levels of amplification to accommodate many downstream molecular assays, even from single cells. For example, droplet digital PCR (with or without reverse transcription, RNA or DNA, respectively) provides absolute quantification of gene expression or detection of mutations. Droplet digital PCR offers high sensitivity and reproducibility ${ }^{164}$ and eliminates variabilities with endogenous controls. ${ }^{165}$ Exome-targeted next generation sequencing (NGS) used to evaluate multiple exon regions for mutations ${ }^{166}$ requires an input of $\sim 30 \mathrm{ng}$ of DNA, which can be secured using WGA. Employing WGA can address the challenge of input mass requirements, however, it may create other challenges, including (i) Bias representation of the genome. Owing to the high GC content of the human genome and high numbers of 
repetitive elements, the genome is biased in terms of its representation following amplification. ${ }^{167}$ While researchers have reported single-cell sequencing with WGA, the success rate of library preparation becomes a challenge and to minimize this issue, $>20$ cells are required. ${ }^{168}$ (ii) Short reads ( $<300 \mathrm{bp}$ ). Short reads can be problematic because of the inability to deduce the presence of large structural variations, ${ }^{169}$ the difficulty with mapping single-nucleotide polymorphisms (SNPs) in long repetitive regions of the genome, ${ }^{170}$ and the inability to do haplotyping. ${ }^{171}$ Also, genomes assembled de novo are of lower quality using short reads when compared to longer reads. ${ }^{172}$

The answer to many of the aforementioned challenges can be single-molecule sequencing (SMS). ${ }^{173-195}$ Examples of SMS platforms include Helicos, ${ }^{196}$ Genia, ${ }^{197,198}$ Pacific Biosystems, ${ }^{199,200}$ and Oxford Nanopore. ${ }^{201-205}$ While single molecules are sequenced, unfortunately, in many cases amplification is still needed to accommodate the necessary input mass requirements; the MinIon requires an input mass of $\sim 1 \mu \mathrm{g}$ of DNA.

Protein-based assays from enriched cells can include immunofluorescence with high sensitivity microscopy, ${ }^{206}$ Western Blotting, ${ }^{207}$ or mass spectrometry. ${ }^{208,209}$ Immunophenotyping of even single cell using microscopy is frequently used but is labor intensive and requires affinity agents that target specific proteins of interest. ${ }^{206,210}$ Western blotting can be labor intensive, however, methods have been reported that use microfluidics for Western blotting. ${ }^{210}$ Finally, mass spectrometry requires input masses that are typically greater than $500 \mathrm{fM}$, which can create significant analytical challenges when single cells must be analyzed.

Therefore, new concepts for molecular profiling must evolve to accommodate the mass limits associated with the enrichment of rare cells from a variety of samples. For example, we are developing a novel single-molecule sequencing strategy that does not require PCR amplification. The concept is based on using a nanofluidic network to measure the electrophoretic mobility of single nucleotides sequentially released from intact DNA molecules using a surface-immobilized exonuclease. ${ }^{211}$ In the case of proteins, methods for single molecule identification have been devised, which use fluorescence labeling of cysteine and lysine residues. ${ }^{212}$ Peptides are placed on glass slides and by using total internal reflection microscopy, a loss of fluorescence is monitored during Edman degradation of peptide fragments to allow for identification. Single-molecule methods will not only allow for the identification of DNAs, RNAs, and proteins but can also provide quantitative information in a digital format, similar to what is done in the case of droplet digital PCR.

Coupled with new single-molecule processing strategies, the evolution of microfluidics to provide processing step integration will be important to realize seamless processing of rare cells following enrichment. For example, in this review we highlighted publications that have coupled cell separation/sorting technologies with downstream processing steps of the enriched cells. The primary advantage of building integrated systems is that they obviate the need for the operator to handle rare cells that can result in sample loss, contamination, or cell damage. In addition, the automation delivered by integrated systems will realize the use of these systems at the point-of-use and move forward distributive medicine in which 
sophisticated molecular assays using liquid biopsy markers would allow for these assays to be carried out by novice operators and in remote settings.

\section{ACKNOWLEDGMENTS}

The authors thank the NIH for financial support of this work via NIBIB Grant P41-EB020594 and COBRE Grant 5P20GM130423.

\section{Biographies}

Malgorzata A. Witek is an Associate Research Professor in the Department of Chemistry at the University of Kansas and an Adjunct Research Professor in the Department of Biomedical Engineering at the University of North Carolina, Chapel Hill. She received M.Sc. in 1997 from Silesian University of Technology in Gliwice, Poland, and earned a Ph.D. in Analytical Chemistry in 2002 from Michigan State University. Her current research interests involve microfluidic-based isolation and molecular analysis of liquid biopsy markers including immune cells, circulating solid tumor and leukemia cells, extracellular vesicles, and cell free DNA for immunotherapies, cancer, and stroke diagnostics.

Ian M. Freed received his B.S. degree in Chemistry from Saint Louis University in 2018. $\mathrm{He}$ is now a graduate student at the University of Kansas in the Prof. Steven A. Soper research group. He is currently working on an impedance-based microfluidic device to instantaneously assess the viability of single cells and also working in conjunction with The University of Kansas Medical Center on longitudinal studies evaluating circulating tumor cells in cancer patients enrolled in clinical trials evaluating novel chemotherapy treatment.

Steven A. Soper received his Ph.D. from the University of Kansas in 1989 followed by a Postdoctoral Fellowship at Los Alamos National Laboratory, where he worked on singlemolecule detection for high-speed sequencing of the human genome. In 1991, he joined the faculty at Louisiana State University (LSU) within the Department of Chemistry, where he filled the William H. Pryor Distinguished Chair of Chemistry. Prof. Soper also held joint appointments in Mechanical Engineering and Biological Sciences. While at LSU, he founded the Center of BioModular Multi-Scale Systems for Precision Medicine, which has as its primary charge to develop enabling and transformative tools for making health-related measurements from rare disease markers, such as liquid biopsy markers, with full process automation. This Center has recently been awarded funding from the National Institutes of Health as part of their Biotechnology Resource Center Program (funded through the National Institute of Biomedical Imaging and Bioengineering). In 2011, Prof. Soper accepted a position within the Department of Biomedical Engineering and Department of Chemistry at the University of North Carolina, Chapel Hill. Prof. Soper is currently a Foundation Distinguished Professor in Chemistry and Mechanical Engineering at the University of Kansas, Lawrence. Prof. Soper also holds an appointment at Ulsan National Institute of Science and Technology in Ulsan, South Korea, where he is a World Class University Professor. He is also serving as a Science Advisor for a number of major worldwide companies. Prof. Soper is also serving as a permanent Member of the Nanotechnology study panel with the National Institutes of Health. 


\section{REFERENCES}

(1). Jameson JL; Longo DL N. Engl. J. Med 2015, 372, 2229-2234. [PubMed: 26014593]

(2). Macias M; Alegre E; Diaz-Lagares A; Patino A; Perez-Gracia JL; Sanmamed M; Lopez-Lopez R; Varo N; Gonzalez A In Advances in Clinical Chemistry, Vol. 83; Makowski GS; Elsevier, 2018; pp 73-119.

(3). Jeffrey SS; Toner M Lab Chip 2019, 19, 548. [PubMed: 30688954]

(4). Bedard PL; Hansen AR; Ratain MJ; Siu LL Nature 2013, 501, 355. [PubMed: 24048068]

(5). Brooks JD Genome Res. 2012, 22, 183-187. [PubMed: 22301132]

(6). Allard WJ; Matera J; Miller MC; Repollet M; Connelly MC; Rao C; Tibbe AG; Uhr JW; Terstappen LW Clin. Cancer Res 2004, 10, 6897-6904. [PubMed: 15501967]

(7). Alix-Panabières C; Pantel K Cancer Discovery 2016, 6, 479-491. [PubMed: 26969689]

(8). Bardelli A; Pantel K Cancer Cell 2017, 31, 172-179. [PubMed: 28196593]

(9). Allard WJ; Matera J; Miller MC; Repollet M; Connelly MC; Rao C; Tibbe AGJ; Uhr JW; Terstappen LWMM Clin. Cancer Res 2004, 10, 6897-6904. [PubMed: 15501967]

(10). Young B Wheater's Functional Histology: A Text and Colour Atlas, 5th ed.; Churchill Livingstone/Elsevier: London, England, 2006; p x, 437 pages.

(11). Campos CDM; Jackson JM; Witek MA; Soper SA Cancer J. 2018, 24, 93-103. [PubMed: 29601336]

(12). Grindberg RV; Yee-Greenbaum JL; McConnell MJ; Novotny M; O’Shaughnessy AL; Lambert GM; Araúzo-Bravo MJ; Lee J; Fishman M; Robbins GE; Lin X; Venepally P; Badger JH; Galbraith DW; Gage FH; Lasken RS Proc. Natl. Acad. Sci. U. S. A 2013, 110, 19802-19807. [PubMed: 24248345]

(13). Liu Y; Yao J; Walther-Antonio M Biomicrofluidics 2019, 13, 034109. [PubMed: 31149320]

(14). Tian HC; Benitez JJ; Craighead HG PLoS One 2018, 13, e0191520. [PubMed: 29432426]

(15). Kannan S; Miyamoto M; Lin BL; Zhu R; Murphy S; Kass DA; Andersen P; Kwon C Circ. Res 2019, 125, 567-569. [PubMed: 31415233]

(16). Lee KS; Palatinszky M; Pereira FC; Nguyen J; Fernandez VI; Mueller AJ; Menolascina F; Daims H; Berry D; Wagner M; Stocker R Nat. Microbiol 2019, 4, 1035-1048. [PubMed: 30886359]

(17). Ng AHC; Peng S; Xu AM; Noh WJ; Guo K; Bethune MT; Chour W; Choi J; Yang S; Baltimore D; Heath JR Lab Chip 2019, 19, 3011-3021. [PubMed: 31502632]

(18). Verboom K; Everaert C; Yigit N; Rombaut D; Anckaert J; et al. Nucleic Acids Res. 2019, 47, e93. [PubMed: 31216024]

(19). Lundgren A; Fast BJ; Block S; Agnarsson B; Reimhult E; Gunnarsson A; Hook F Nano Lett. 2018, 18, 381-385. [PubMed: 29231738]

(20). Ghuman AP; Zhou Y; Liu Y; Mao L; Ramasamy RP ECS Trans. 2018, 85, 1475-1480.

(21). Hanson C; Barney JT; Bishop MM; Vargis E Electrophoresis 2019, 40, 1446-1456. [PubMed: 30892709]

(22). Jing X; Gou H; Gong Y; Su X; Xu L; Ji Y; Song Y; Thompson IP; Xu J; Huang WE Environ. Microbiol 2018, 20, 2241-2255. [PubMed: 29727057]

(23). Landry ZC; Vergin K; Mannenbach C; Block S; Yang Q; Blainey P; Carlson C; Giovannoni S Front. Microbiol 2018, 9, 1152. [PubMed: 29937754]

(24). Oh S; Jung SH; Seo H; Min M-K; Kim B; Hahn YK; Kang JH; Choi S Sens. Actuators, B 2018, 272, 324-330.

(25). Qiu Y; Zhang J; Wen X; Huang X; Li B; Liang P Sci. Total Environ 2018, 642, 582-590. [PubMed: 29909325]

(26). Schaerli Y Bio-Protoc. 2018, 8, e2911. [PubMed: 30023409]

(27). Tay A; Pfeiffer D; Rowe K; Tannenbaum A; Popp F; Strangeway R; Schuler D; Di Carlo D Appl. Environ. Microbiol 2018, 84, e01308. [PubMed: 29959254]

(28). Keinan E; Abraham AC; Cohen A; Alexandrov AI; Mintz R; Cohen M; Reichmann D; Kaganovich D; Nahmias Y Sci. Rep 2018, 8, 13739. [PubMed: 30214051]

(29). Yu BY; Elbuken C; Shen C; Huissoon JP; Ren CL Sci. Rep 2018, 8, 3550. [PubMed: 29476103] 
(30). Murray C; Miwa H; Dhar M; Park DE; Pao E; Martinez J; Kaanumale S; Loghin E; Graf J; Rhaddassi K; Kwok WW; Hafler D; Puleo C; Di Carlo D Lab Chip 2018, 18, 2396-2409. [PubMed: 30039125]

(31). Reyes M; Vickers D; Billman K; Eisenhaure T; Hoover P; Browne EP; Rao DA; Hacohen N; Blainey PC Sci. Adv 2019, 5, eaau9223. [PubMed: 30746468]

(32). Jiao Y; He Y; Jiao F Micromachines 2019, 10, 393.

(33). Honrado C; Ciuffreda L; Spencer D; Ranford-Cartwright L; Morgan HJR Soc., Interface 2018, 15, 20180416. [PubMed: 30333248]

(34). Thege FI; Gruber CN; Cardle II; Cong SH; Lannin TB; Kirby BJ Anal. Biochem 2019, 577, $26-$ 33. [PubMed: 30790546]

(35). Green BJ; Nguyen V; Atenafu E; Weeber P; Duong BTV; Thiagalingam P; Labib M; Mohamadi RM; Hansen AR; Joshua AM; Kelley SO Anal. Chem. (Washington, DC, U. S.) 2019, 91, 93489355.

(36). Green BJ; Kermanshah L; Labib M; Ahmed SU; Silva PN; Mahmoudian L; Chang IH; Mohamadi RM; Rocheleau JV; Kelley SO ACS Appl. Mater. Interfaces 2017, 9, 20435-20443. [PubMed: 28548481]

(37). Kang Y-T; Kim YJ; Bu J; Chen S; Cho Y-H; Lee HM; Ryu CJ; Lim Y; Han S-W Sens. Actuators, B 2018, 260, 320-330.

(38). Dasanna AK; Schwarz US Soft Matter 2018, 14, 9061-9070. [PubMed: 30394471]

(39). Li T; Li N; Ma Y; Bai Y-J; Xing C-M; Gong Y-KJ Mater. Chem. B 2019, 7, 6087-6098.

(40). Chen K; Dopico P; Varillas J; Zhang J; George TJ; Fan ZH Angew. Chem., Int. Ed 2019, 58, 7606-7610.

(41). Zeinali M; Murlidhar V; Fouladdel S; Shao S; Zhao L; Cameron H; Bankhead A III; Shi J; Cuneo KC; Sahai V; Azizi E; Wicha MS; Hafner M; Simeone DM; Nagrath S Adv. Biosyst 2018, 2, 1800228.

(42). Kamande JW; Lindell MAM; Witek MA; Voorhees PM; Soper SA Integr Biol. (Camb) 2018, 10, 82-91. [PubMed: 29372735]

(43). Birmingham KG; O’Melia MJ; Ban D; Mouw J; Edwards EE; Marcus AI; McDonald J; Thomas SN Adv. Biosyst 2019, 3, 1800328.

(44). Varillas JI; Zhang J; Chen K; Barnes II; Liu C; George TJ; Fan ZH Theranostics 2019, 9, 1417 1425. [PubMed: 30867841]

(45). Kim TH; Yoon HJ; Fouladdel S; Wang Y; Kozminsky M; Burness ML; Paoletti C; Zhao L; Azizi E; Wicha MS; Nagrath S Adv. Biosyst 2019, 3, 1800278.

(46). Reinholt SJ; Craighead HG Anal. Chem 2018, 90, 2601-2608. [PubMed: 29323871]

(47). Chen Y-H; Pulikkathodi AK; Ma Y-D; Wang Y-L; Lee G-B Lab Chip 2019, 19, 618-625. [PubMed: 30644487]

(48). Liao C-J; Hung F-C; Chou W-P; Wu M-H; Hsieh C-H; Wang H-M; Wu M-H; Wu M-H Cancers $2019,11,783$.

(49). LeValley PJ; Tibbitt MW; Noren B; Kharkar P; Kloxin AM; Anseth KS; Toner M; Oakey J Colloids Surf., B 2019, 174, 483-492.

(50). Wu M; Ozcelik A; Rufo J; Wang Z; Fang R; Jun Huang T Microsyst. Nanoeng 2019, 5, 32. [PubMed: 31231539]

(51). Wu M; Huang P-H; Zhang R; Mao Z; Chen C; Kemeny G; Li P; Lee AV; Gyanchandani R; Armstrong AJ; Dao M; Suresh S; Huang TJ Small 2018, 14, No. 1801131.

(52). Wu M; Chen K; Yang S; Wang Z; Huang P-H; Mai J; Li Z-Y; Huang TJ Lab Chip 2018, 18, 3003-3010. [PubMed: 30131991]

(53). Gnyawali V; Strohm EM; Wang J-Z; Tsai SSH; Kolios MC Sci. Rep 2019, 9, 1585. [PubMed: 30733497]

(54). Wang K; Zhou W; Lin Z; Cai F; Li F; Wu J; Meng L; Niu L; Zheng H Sens. Actuators, B 2018, 258, 1174-1183.

(55). Karthick S; Pradeep PN; Kanchana P; Sen AK Lab Chip 2018, 18, 3802-3813. [PubMed: 30402651] 
(56). Gonzalez I; Pinto A; Earl J; Carrato A; Fernandez LJ; Monge R; Sainz B; Alcala S; Castillejo A; Soto JL Micromachines 2018, 9, 129.

(57). Garg N; Westerhof TM; Liu V; Liu R; Nelson EL; Lee AP Microsyst. Nanoeng 2018, 4, 17085.

(58). Shamloo A; Boodaghi M Ultrasonics 2018, 84, 234-243. [PubMed: 29175517]

(59). Shamloo A; Parast FY IEEE Trans. Electron Devices 2019, 66, 1495-1503.

(60). Liu H; Ao Z; Cai B; Shu X; Chen K; Rao L; Luo C; Wang F-B; Liu W; Bondesson M; Guo S; Guo F Nano Futures 2018, 2, 025004.

(61). Mutafopulos K; Spink P; Lofstrom CD; Lu PJ; Lu H; Sharpe JC; Franke T; Weitz DA Lab Chip 2019, 19, 2435-2443. [PubMed: 31192328]

(62). Ren L; Chen Y; Yang S; Zhang P; Huang P-H; Wu M; Huang TJ; Qu Z; Mao Z; Wang L; Li P Small 2018, 14, No. 1801996.

(63). Lee LM; Rosano JM; Wang Y; Klarmann GJ; Garson CJ; Prabhakarpandian B; Pant K; Alvarez LM; Lai E Anal. Methods 2018, 10, 713-721.

(64). Kwon T; Yao R; Hamel J-FP; Han J Lab Chip 2018, 18, 2826-2837. [PubMed: 30079919]

(65). Khoo BL; Bouquerel C; Bouquerel C; Lim CT; Durai P; Goh B; Chiong E; Anil S; Lim CT; Wu B; Thamboo T; Raman L; Mahendran R; Chiong E; Lim CT; Lim CT Cancers 2019, 11, 1274.

(66). Tee CA; Yang Z; Yin L; Wu Y; Han J; Lee EH Biomaterials 2019, 220, 119409. [PubMed: 31404789]

(67). Fuchs BB; Eatemadpour S; Mylonakis E; Martel-Foley JM; Stott S; Toner M Front. Cell. Infect. Microbiol 2019, 9, 27. [PubMed: 30809512]

(68). Syverud BC; Lin E; Nagrath S; Larkin LM Tissue Eng., Part C 2018, 24, 32-41.

(69). Vaidyanathan R; Yeo T; Lim CT Methods Cell Biol. 2018, 147, 151-173. [PubMed: 30165956]

(70). Hazra S; Jayaprakash KS; Pandian K; Raj A; Mitra SK; Sen AK Analyst (Cambridge, U. K.) 2019, 144, 2574-2583.

(71). Li M; van Zee M; Goda K; Di Carlo D Lab Chip 2018, 18, 2575-2582. [PubMed: 30046787]

(72). Bleilevens C; Lolsberg J; Cinar A; Knoben M; Grottke O; Rossaint R; Wessling M Sci. Rep 2018, 8, 8031. [PubMed: 29795137]

(73). Deng P; Fu C-J; Wu Z RSC Adv. 2018, 8, 35512-35520.

(74). Pritchard RH; Zhukov AA; Fullerton JN; Want AJ; Hussain F; la Cour MF; Bashtanov ME; Gold RD; Hailes A; Banham-Hall E; Rogers SS Lab Chip 2019, 19, 2456-2465. [PubMed: 31210196]

(75). Zhou Y; Ma Z; Ai Y Microsyst. Nanoeng 2018, 4, 5. [PubMed: 31057895]

(76). Lemaire CA; Liu SZ; Wilkerson CL; Ramani VC; Barzanian NA; Huang K-W; Che J; Chiu MW; Vuppalapaty M; Dimmick AM; Carlo DD; Kochersperger ML; Crouse SC; Jeffrey SS; Englert RF; Hengstler S; Renier C; Sollier-Christen E SLAS Technol. 2018, 23, 16-29. [PubMed: 29355087]

(77). Chien W; Zhang Z; Gompper G; Fedosov DA Biomicrofluidics 2019, 13, 044106. [PubMed: 31372194]

(78). Xiang N; Wang J; Li Q; Han Y; Huang D; Ni Z Anal. Chem. (Washington, DC, U. S.) 2019, 91, $10328-10334$.

(79). Wang X; Sun L; Zhang H; Wei L; Qu W; Zeng Z; Liu Y; Zhu Z PeerJ 2019, 7, No. e6681. [PubMed: 30972256]

(80). Jiang X; Wong KHK; Khankhel AH; Zeinali M; Reategui E; Phillips MJ; Luo X; Aceto N; Fachin F; Hoang AN; Kim W; Jensen AE; Sequist LV; Maheswaran S; Haber DA; Stott SL; Toner M Lab Chip 2017, 17, 3498-3503. [PubMed: 28932842]

(81). Gomis S; Labib M; Coles BLK; van der Kooy D; Sargent EH; Kelley SO ACS Appl. Mater. Interfaces 2018, 10, 34811-34816. [PubMed: 30265796]

(82). Xavier M; Holm SH; Beech JP; Spencer D; Tegenfeldt JO; Oreffo ROC; Morgan H Lab Chip 2019, 19, 513-523. [PubMed: 30632599]

(83). Strachan BC; Xia HUI; VÖRÖS E; Gifford SC; Shevkoplyas SS Cytotherapy 2019, 21, 234-245. [PubMed: 30660490] 
(84). Fachin F; Spuhler P; Martel-Foley JM; Edd JF; Barber TA; Walsh J; Karabacak M; Pai V; Yu M; Smith K; Hwang H; Yang J; Shah S; Yarmush R; Sequist LV; Stott SL; Maheswaran S; Haber DA; Kapur R; Toner M Sci. Rep 2017, 7, 10936. [PubMed: 28883519]

(85). Sun Y; Sethu P; Sun Y; Sethu P Biomed. Microdevices 2018, 20, 77. [PubMed: 30155743]

(86). Yu L; Sa S; Wang L; Dulmage K; Bhagwat N; Yee SS; Sen M; Pletcher CH Jr.; Moore JS; Saksena S; Dixon EP; Carpenter EL Cytometry, Part A 2018, 93, 1226-1233.

(87). Tay A; Pfeiffer D; Rowe K; Tannenbaum A; Popp F; Strangeway R; Schuler D; Di Carlo D Appl. Environ. Microbiol 2018, DOI: 10.1128/AEM.01308-18.

(88). Kokkinis G; Cardoso S; Keplinger F; Giouroudi I Sens. Actuators, B 2017, 241, 438-445.

(89). Kye HG; Park BS; Lee JM; Song MG; Song HG; Ahrberg CD; Chung BG Sci. Rep 2019, 9, 9502. [PubMed: 31263123]

(90). Chen H; Zhang Z; Liu H; Zhang Z; Lin C; Wang B AIP Adv. 2019, 9, 025023.

(91). Huang N-T; Hwong Y-J; Lai RL Microfluid. Nanofluid 2018, 22, 16.

(92). Xu H; Dong B; Xu S; Xu S; Sun X; Sun J; Yang Y; Xu L; Bai X; Zhang S; Yin Z; Song H Biomaterials 2017, 138, 69-79. [PubMed: 28554009]

(93). Zhao W; Liu Y; Jenkins BD; Cheng R; Harris BN; Zhang W; Xie J; Murrow JR; Hodgson J; Egan M; Bankey A; Nikolinakos PG; Ali HY; Meichner K; Newman LA; Davis MB; Mao L Lab Chip 2019, 19, 1860-1876. [PubMed: 31041975]

(94). de Wijs K; Liu C; Dusa A; Vercruysse D; Majeed B; Tezcan DS; Blaszkiewicz K; Loo J; Lagae L Lab Chip 2017, 17, 1287-1296. [PubMed: 28252674]

(95). Zhao J; You Z Cytometry, Part A 2018, 93, 222-231.

(96). Okumus B; Baker CJ; Arias-Castro JC; Lai GC; Leoncini E; Bakshi S; Luro S; Landgraf D; Paulsson J Nat. Protoc 2018, 13, 170-194. [PubMed: 29266097]

(97). Isozaki A; Mikami H; Hiramatsu K; Sakuma S; Kasai Y; et al. Nat. Protoc 2019, 14, 2370-2415. [PubMed: 31278398]

(98). Nagata MPB; Endo K; Ogata K; Yamanaka K; Egashira J; Katafuchi N; Yamanouchi T; Matsuda H; Goto Y; Sakatani M; Hojo T; Nishizono H; Yotsushima K; Takenouchi N; Hashiyada Y; Yamashita K Proc. Natl. Acad. Sci. U. S. A 2018, 115, E3087-E3096. [PubMed: 29555773]

(99). Ceffa NG; Bouzin M; D’Alfonso L; Sironi L; Marquezin CA; Auricchio F; Marconi S; Chirico G; Collini M Anal. Chem. (Washington, DC, U. S.) 2018, 90, 2277-2284.

(100). Hamza B; Ng SR; Prakadan SM; Delgado FF; Chin CR; et al. Proc. Natl. Acad. Sci. U. S. A 2019, 116, 2232-2236. [PubMed: 30674677]

(101). Edwards EE; Birmingham KG; O’Melia MJ; Oh J; Thomas SN Cell Syst. 2018, 7, 496. [PubMed: 30414924]

(102). Gu Y; Zhang AC; Han Y; Lo Y-H; Li J; Chen C Cytometry, Part A 2019, 95, 499-509.

(103). Nitta N; Sugimura T; Isozaki A; Mikami H; Hiraki K; et al. Cell 2018, 175, 266. [PubMed: 30166209]

(104). Hamza B; Hamza B; Ng SR; Prakadan SM; Delgado FF; et al. Proc. Natl. Acad. Sci. U. S. A 2019, 116, 2232-2236. [PubMed: 30674677]

(105). Hu X; Zhu D; Chen M; Chen K; Liu H; Liu W; Yang Y Lab Chip 2019, 19, 2549-2556. [PubMed: 31263813]

(106). Liu S; Li Z; Weng Z; Li Y; Shui L; Jiao Z; Chen Y; Luo A; Xing X; He S Opt. Lett 2019, 44, 1868-1871. [PubMed: 30933168]

(107). Tkachenko G; Stellinga D; Ruskuc A; Chen M; Dholakia K; Krauss TF Opt. Lett 2018, 43, 3224-3227. [PubMed: 30004537]

(108). Schneider T; Kreutz J; Chiu DT Anal. Chem 2013, 85, 3476-3482. [PubMed: 23495853]

(109). Xi H-D; Zheng H; Guo W; Gañán-Calvo AM; Ai Y; Tsao C-W; Zhou J; Li W; Huang Y; Nguyen N-T; Tan SH Lab Chip 2017, 17, 751-771. [PubMed: 28197601]

(110). Jyoti Dipanka Shaikeea A; Basu S; Bansal LJ Colloid Interface Sci. 2018, 512, 497-510.

(111). Turk-MacLeod R; Henson A; Rodriguez-Garcia M; Gibson GM; Aragon Camarasa G; Caramelli D; Padgett MJ; Cronin L Proc. Natl. Acad. Sci. U. S. A 2018, 115, 5681-5685. [PubMed: 29760051] 
(112). Yu Z; Boehm CR; Hibberd JM; Abell C; Haseloff J; Burgess SJ; Reyna-Llorens I PLoS One 2018, 13, e0196810. [PubMed: 29723275]

(113). Pan CW; Horvath DG; Braza S; Moore T; Lynch A; Feit C; Abbyad P Lab Chip 2019, 19, 1344-1351. [PubMed: 30849144]

(114). Shembekar N; Hu H; Eustace D; Merten CA Cell Rep. 2018, 22, 2206-2215. [PubMed: 29466744]

(115). Navi M; Abbasi N; Jeyhani M; Gnyawali V; Tsai SSH Lab Chip 2018, 18, 3361-3370. [PubMed: 30375625]

(116). Li P; Ma Z; Zhou Y; Collins DJ; Wang Z; Ai Y Anal. Chem. (Washington, DC, U. S.) 2019, 91, 9970-9977.

(117). Kim SC; Clark IC; Shahi P; Abate AR Anal. Chem. (Washington, DC, U. S.) 2018, 90, $1273-$ 1279.

(118). Chung MT; Kurabayashi K; Cai D Lab Chip 2019, 19, 2425-2434. [PubMed: 31187105]

(119). Segaliny AI; Li G; Kong L; Ren C; Chen X; Wang JK; Baltimore D; Wu G; Zhao W Lab Chip 2018, 18, 3733-3749. [PubMed: 30397689]

(120). Ahmadi F; Samlali K; Vo PQN; Shih SCC Lab Chip 2019, 19, 524-535. [PubMed: 30633267]

(121). Li X; Zhang D; Zhang H; Guan Z; Song Y; Liu R; Zhu Z; Yang C Anal. Chem. (Washington, DC, U. S.) 2018, 90, 2570-2577.

(122). Qin Y; Wu L; Wang J; Han R; Shen J; Wang J; Xu S; Paguirigan AL; Smith JL; Radich JP; Chiu DT Anal. Chem 2019, 91, 6815-6819. [PubMed: 31050286]

(123). Buryk-Iggers S; Kieda J; Tsai SSH AIP Adv. 2019, 9, 075106.

(124). Zhu Y; Clair G; Chrisler WB; Shen Y; Zhao R; Shukla AK; Moore RJ; Misra RS; Pryhuber GS; Smith RD; Ansong C; Kelly RT Angew. Chem., Int. Ed 2018, 57, 12370-12374.

(125). Utharala R; Tseng Q; Furlong EEM; Merten CA Anal. Chem. (Washington, DC, U. S.) 2018, 90, 5982-5988.

(126). Chen Y; Li Y; Li D; Li J; Chen H Microfluid. Nanofluid 2019, 23, 25.

(127). Yuan D; Sluyter R; Zhao Q; Tang S; Yan S; Yun G; Li M; Zhang J; Li W Microfluid. Nanofluid 2019, 23, 41.

(128). Du M; Kavanagh D; Kalia N; Zhang Z Med. Eng. Phys 2019, 73, 18. [PubMed: 31405755]

(129). Islam M; Mezencev R; McFarland B; Brink H; Campbell B; Tasadduq B; Waller EK; Lam W; Alexeev A; Sulchek T Cell Death Dis. 2018, 9, 239. [PubMed: 29445159]

(130). Bongiorno T; Gura J; Talwar P; Chambers D; Young KM; Arafat D; Wang G; Jackson-Holmes EL; Qiu P; McDevitt TC; Sulchek T PLoS One 2018, 13, No. e0192631. [PubMed: 29518080]

(131). Girardo S; Traeber N; Wagner K; Cojoc G; Herold C; Goswami R; Schluessler R; Abuhattum S; Taubenberger A; Reichel F; Mokbel D; Herbig M; Schuermann M; Mueller P; Heida T; Jacobi A; Ulbricht E; Thiele J; Werner C; Guck JJ Mater. Chem. B 2018, 6, 6245-6261.

(132). Yang C; Zhang N; Wang S; Shi D; Zhang C; Liu K; Xiong BJ Transl. Med 2018, 16, 139.

(133). Qiu X; Lombardo JA; Westerhof TM; Pennell M; Ng A; Alshetaiwi H; Luna BM; Nelson EL; Kessenbrock K; Hui EE; Haun JB Lab Chip 2018, 18, 2776-2786. [PubMed: 30090895]

(134). Ren J; Li J; Li Y; Xiao P; Liu Y; Tsang CM; Tsao SW; Lau D; Chan KWY; Lam RHW ACS Biomater. Sci. Eng 2019, 5, 3889-3898.

(135). Yanai T; Ouchi T; Yamada M; Seki M Micromachines (Basel) 2019, 10, 425.

(136). Weng L; Ellett F; Edd J; Wong KHK; Uygun K; Irimia D; Stott SL; Toner M Lab Chip 2017, 17, 4077-4088. [PubMed: 29068447]

(137). Ozawa R; Iwadate H; Toyoda H; Yamada M; Seki M Lab Chip 2019, 19, 1828-1837. [PubMed: 30998230]

(138). Mehendale N; Sharma O; D’Costa C; Paul D Biomed. Microdevices 2018, 20, 6.

(139). Kamyabi N; Huang J; Lee JJ; Bernard V; Semaan A; Stephens B; Hurd MW; Vanapalli SA; Maitra A; Guerrero PA Biomicrofluidics 2019, 13, 044111. [PubMed: 31462955]

(140). Miller MC; Robinson PS; Wagner C; O’Shannessy DJ Cytometry, Part A 2018, 93, 1234-1239.

(141). Wang K; Zhou L; Zhao S; Cheng Z; Qiu S; Lu Y; Wu Z; Abdel Wahab AHA; Mao H; Zhao J Talanta 2019, 200, 169-176. [PubMed: 31036170] 
(142). Pohl HA J. Appl. Phys 1951, 22, 869-871.

(143). Pethig R Biomicrofluidics 2010, 4, 022811. [PubMed: 20697589]

(144). Puri P; Belgamwar SU; Kumar V; Sharma NN Biomed. Microdevices 2018, 20, 102. [PubMed: 30536135]

(145). Adams TNG; Jiang AYL; Vyas PD; Flanagan LA Methods (Amsterdam, Neth.) 2018, 133, 91103.

(146). Shuchat S; Park S; Yossifon G; Kol S Electrophoresis 2019, 40, 1606-1614. [PubMed: 30892707]

(147). Xing X; Ng CN; Chau ML; Yobas L Lab Chip 2018, 18, 3760-3769. [PubMed: 30403217]

(148). Wu Y; Ren Y; Tao Y; Hou L; Jiang H Anal. Chem. (Washington, DC, U. S.) 2018, 90, 1146111469.

(149). Yao J; Chen J; Cao X; Dong H Talanta 2019, 196, 546-555. [PubMed: 30683404]

(150). Chiou PY; Ohta AT; Wu MC Nature 2005, 436, 370-372. [PubMed: 16034413]

(151). Chiu T-K; Chao AC; Chou W-P; Liao C-J; Wang H-M; Chang J-H; Chen P-H; Wu M-H Sens. Actuators, B 2018, 258, 1161-1173.

(152). Liao C-J; Hsieh C-H; Chiu T-K; Zhu Y-X; Wang H-M; Hung F-C; Chou W-P; Wu M-H Micromachines (Basel) 2018, 9, 563.

(153). Thomas RSW; Mitchell PD; Oreffo ROC; Morgan H; Green NG Electrophoresis 2019, 40, 2718-2727. [PubMed: 31206722]

(154). Solsona M; Westerbeek EY; Bomer JG; Olthuis W; van den Berg A Lab Chip 2019, 19, 1054 1059. [PubMed: 30768116]

(155). Petchakup C; Tay HM; Yeap WH; Dalan R; Wong SC; Li KHH; Hou HW Biosens. Bioelectron 2018, 118, 195-203. [PubMed: 30077872]

(156). Yang D; Ai Y Lab Chip 2019, 19, 3609-3617. [PubMed: 31517354]

(157). Li R; Jia F; Zhang W; Shi F; Fang Z; Zhao H; Hu Z; Wei Z Lab Chip 2019, 19, 3168-3178. [PubMed: 31455953]

(158). Zhang X; Zhu Z; Xiang N; Long F; Ni Z Anal. Chem. (Washington, DC, U. S.) 2018, 90, 42124220.

(159). Di Trapani M; Manaresi N; Medoro G Cytometry, Part A 2018, 93, 1260-1266.

(160). Watanabe M; Kenmotsu H; Ko R; Wakuda K; Ono A; Imai H; Taira T; Naito T; Murakami H; Abe M; Endo M; Nakajima T; Koh Y; Takahashi T Cancer Sci. 2018, 109, 2539-2548. [PubMed: 29900633]

(161). Campos CDM; Jackson JM; Witek MA; Soper SA Cancer J. 2018, 24, 93. [PubMed: 29601336]

(162). Witek MA; Aufforth RD; Wang H; Kamande JW; Jackson JM; et al. Nature Precision Oncology 2017, 1, 24.

(163). Kamande JW; Lindell MAM; Witek MA; Voorhees PM; Soper SA Integrative Biology 2018, 10, 82-91. [PubMed: 29372735]

(164). Chevillet JR; Kang Q; Ruf IK; Briggs HA; Vojtech LN; Hughes SM; Cheng HH; Arroyo JD; Meredith EK; Gallichotte EN; Pogosova-Agadjanyan EL; Morrissey C; Stirewalt DL; Hladik F; Yu EY; Higano CS; Tewari M Proc. Natl. Acad. Sci. U. S. A 2014, 111, 14888-14893. [PubMed: 25267620]

(165). Liu T; Zhang X; Gao S; Jing F; Yang Y; Du L; Zheng G; Li P; Li C; Wang C Oncotarget 2016, 7, 85551-85563. [PubMed: 27888803]

(166). Liu HE; Triboulet M; Zia A; Vuppalapaty M; Kidess-Sigal E; Coller J; Natu VS; Shokoohi V; Che J; Renier C; Chan NH; Hanft VR; Jeffrey SS; Sollier-Christen E npj Genomic Medicine 2017, 2, 34. [PubMed: 29263843]

(167). Aird D; Ross MG; Chen W-S; Danielsson M; Fennell T; Russ C; Jaffe DB; Nusbaum C; Gnirke A Genome Biology 2011, 12, R18. [PubMed: 21338519]

(168). Lohr JG; Adalsteinsson VA; Cibulskis K; Choudhury AD; Rosenberg M; et al. Nat. Biotechnol 2014, 32, 479-484. [PubMed: 24752078]

(169). Norris AL; Workman RE; Fan YF; Eshleman JR; Timp W Cancer Biol. Ther 2016, 17, $246-$ 253. [PubMed: 26787508] 
(170). Treangen TJ; Salzberg SL Nat. Rev. Genet 2012, 13, 36-46.

(171). Huang M; Tu J; Lu Z Int. J. Mol. Sci 2017, 18, 1944.

(172). Schatz MC; Delcher AL; Salzberg SL Genome Res. 2010, 20, 1165-1173. [PubMed: 20508146]

(173). Gupta PK Trends Biotechnol. 2008, 26, 602-611. [PubMed: 18722683]

(174). Clarke J; Wu HC; Jayasinghe L; Patel A; Reid S; Bayley H Nat. Nanotechnol 2009, 4, 265-270. [PubMed: 19350039]

(175). Milos PM Expert Rev. Mol. Diagn 2009, 9, 659-666. [PubMed: 19817551]

(176). Pushkarev D; Neff NF; Quake SR Nat. Biotechnol 2009, 27, 847-U101. [PubMed: 19668243]

(177). Eid J; Fehr A; Gray J; Luong K; Lyle J; Otto G; Peluso P; Rank D; Baybayan P; Bettman B; Bibillo A; Bjornson K; Chaudhuri B; Christians F; Cicero R; Clark S; Dalal R; Dewinter A; Dixon J; Foquet M; et al. Science 2009, 323, 133-138. [PubMed: 19023044]

(178). Braslavsky I Biophys. J 2010, 98, 208A-209A.

(179). Flusberg BA; Webster DR; Lee JH; Travers KJ; Olivares EC; Clark TA; Korlach J; Turner SW Nat. Methods 2010, 7, 461-U472. [PubMed: 20453866]

(180). Sam LT; Lipson D; Raz T; Cao XH; Thompson J; Milos PM; Robinson D; Chinnaiyan AM; Kumar-Sinha C; Maher CA PLoS One 2011, 6, e17305. [PubMed: 21390249]

(181). Thompson JF In Vitro Cell. Dev. Biol.: Anim 2011, 47, S14-S14.

(182). Thompson JF; Milos PM Genome Biol. 2011, 12, 217. [PubMed: 21349208]

(183). Avent ND Clin. Chem 2012, 58, 657-658. [PubMed: 22300629]

(184). van den Oever JME; Balkassmi S; Verweij EJ; van Iterson M; van Scheltema PNA; Oepkes D; van Lith JMM; Hoffer MJV; den Dunnen JT; Bakker E; Boon EM J. Clin. Chem 2012, 58, 699706.

(185). Davis BM; Chao MC; Waldor MK Curr. Opin. Microbiol 2013, 16, 192-198. [PubMed: 23434113]

(186). Shin SC; Ahn DH; Kim SJ; Lee H; Oh TJ; Lee JE; Park H PLoS One 2013, 8, e68824. [PubMed: 23894349]

(187). Patel A; Schwab R; Liu YT; Bafna V Genome Res. 2014, 24, 318-328. [PubMed: 24307551]

(188). Sakai H; Naito K; Ogiso-Tanaka E; Takahashi Y; Iseki K; Muto C; Satou K; Teruya K; Shiroma A; Shimoji M; Hirano T; Itoh T; Kaga A; Tomooka N Sci. Rep 2015, 5, 16780. [PubMed: 26616024]

(189). Steinig EJ; Andersson P; Harris SR; Sarovich DS; Manoharan A; Coupland P; Holden MTG; Parkhill J; Bentley SD; Robinson DA; Tong SYC BMC Genomics 2015, 16, 388. [PubMed: 25981586]

(190). Yang Y; Sebra R; Pullman BS; Qiao WQ; Peter I; Desnick RJ; Geyer CR; DeCoteau JF; Scott SA BMC Genomics 2015, 16, 350. [PubMed: 25943404]

(191). Betz-Stablein BD; Topfer A; Littlejohn M; Yuen L; Colledge D; Sozzi V; Angus P; Thompson A; Revill P; Beerenwinkel N; Warner N; Luciani FJ Virol. 2016, 90, 7171-7183.

(192). Gao Y; Deng LW; Yan Q; Gao YQ; Wu ZD; Cai JS; Ji DR; Li GL; Wu P; Jin H; Zhao LY; Liu S; Ge LJ; Deem MW; He JK Sci. Rep 2016, 6, 26110. [PubMed: 27193446]

(193). Hargreaves KR; Thanki AM; Jose BR; Oggioni MR; Clokie MRJ BMC Genomics 2016, 17, 1020. [PubMed: 27964731]

(194). Kujawa S; Sethuraman A; Eng K; Baybayan P; Heyrman L; Del Favero J Highly sensitive and cost-effective detection of somatic cancer variants using single-molecule, real-time sequencingProceedings: AACR 107th Annual Meeting 2016, New Orleans, LA, April 16-20, 2016; Abstract 3646 ,.

(195). Ozsolak F Current Issues in Molecular Biology 2016, 18, 43-48. [PubMed: 26154140]

(196). Milos PM Genome Biology 2010, 11, I14.

(197). Fuller CW; Kumar S; Porel M; Chien MC; Bibillo A; et al. Proc. Natl. Acad. Sci. U. S. A 2016, 113, 5233-5238. [PubMed: 27091962]

(198). Stranges PB; Palla M; Kalachikov S; Nivala J; Dorwart M; et al. Proc. Natl. Acad. Sci. U. S. A 2016, 113, E6749-E6756. [PubMed: 27729524]

(199). McCarthy A Chem. Biol 2010, 17, 675-676. [PubMed: 20659677] 
(200). Grohme MA; Soler RF; Wink M; Frohme M BioTechniques 2013, 55, 255-258.

(201). Eisenstein M Nat. Biotechnol 2012, 30, 295-296. [PubMed: 22491260]

(202). Goodwin S; Gurtowski J; Ethe-Sayers S; Deshpande P; Schatz MC; McCombie WR Genome Res. 2015, 25, 1750-1756. [PubMed: 26447147]

(203). Hargreaves AD; Mulley JF PeerJ 2015, 3, e1441. [PubMed: 26623194]

(204). Jain M; Olsen HE; Paten B; Akeson M Genome Biol. 2016, 17, 239. [PubMed: 27887629]

(205). Oikonomopoulos S; Wang YC; Djambazian H; Badescu D; Ragoussis J Sci. Rep 2016, 6, 31602. [PubMed: 27554526]

(206). Lin J-R; Fallahi-Sichani M; Sorger PK Nat. Commun 2015, 6, 8390-8390. [PubMed: 26399630]

(207). Hughes AJ; Herr AE Proc. Natl. Acad. Sci. U. S. A 2012, 109, 21450-21455. [PubMed: 23223527]

(208). Dou M; Clair G; Tsai C-F; Xu K; Chrisler WB; Sontag RL; Zhao R; Moore RJ; Liu T; PasaTolic L; Smith RD; Shi T; Adkins JN; Qian W-J; Kelly RT; Ansong C; Zhu Y Anal. Chem 2019, 91, 13119-13127. [PubMed: 31509397]

(209). Budnik B; Levy E; Harmange G; Slavov N Genome Biol. 2018, 19, 161. [PubMed: 30343672]

(210). Hughes AJ; Spelke DP; Xu Z; Kang C-C; Schaffer DV; Herr AE Nat. Methods 2014, 11, 749_ 755. [PubMed: 24880876]

(211). O’Neil C; Amarasekara CA; Weerakoon-Ratnayake KM; Gross B; Jia Z; Singh V; Park S; Soper SA Anal. Chim. Acta 2018, 1027, 67-75. [PubMed: 29866271]

(212). Swaminathan J; Boulgakov AA; Hernandez ET; Bardo AM; Bachman JL; Marotta J; Johnson AM; Anslyn EV; Marcotte EM Nat. Biotechnol 2018, 36, 1076-1082. 


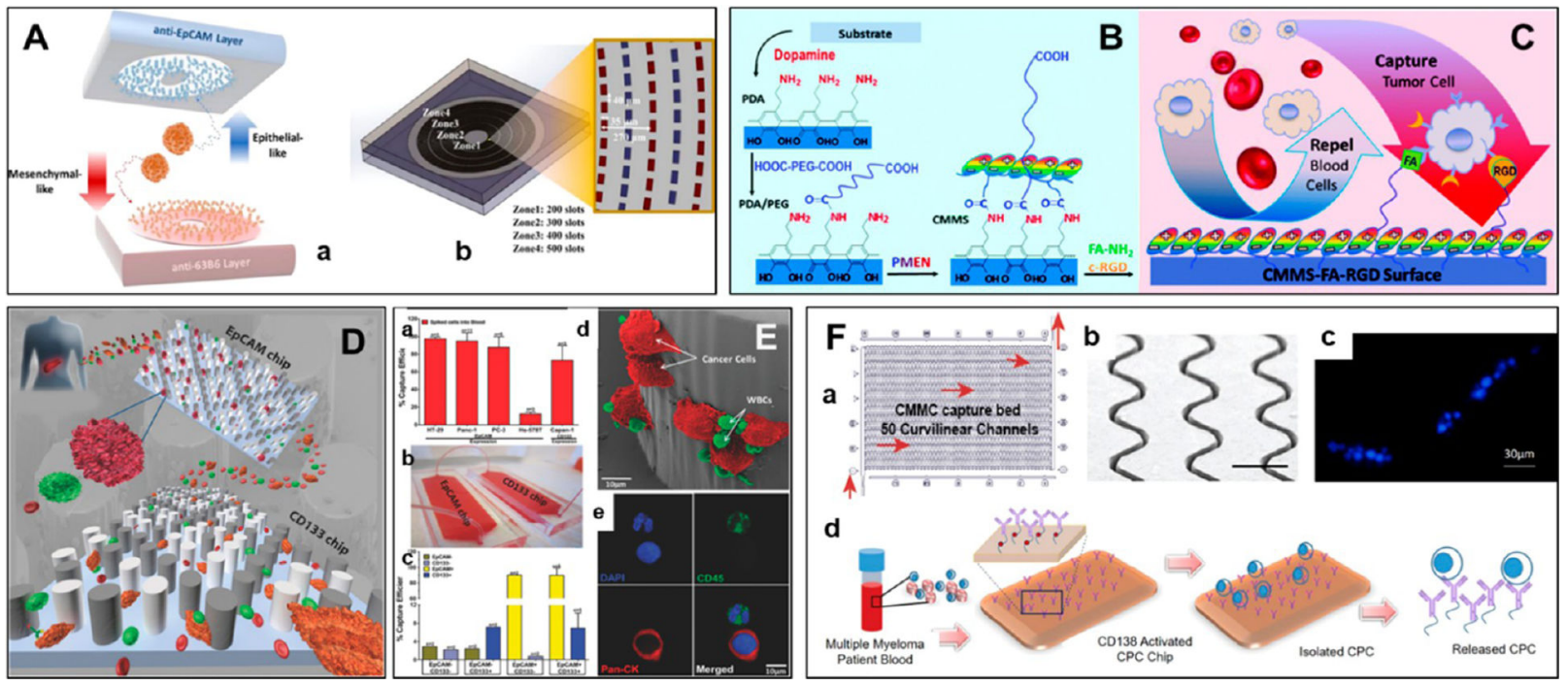

Figure 1.

Cell affinity-isolation methods. (A) Schematic of the dual-immunopatterned (DIP) device composed of an anti-EpCAM antibody-immobilized layer and an anti-63B6 antibodyimmobilized layer. (a) Device concept and working mechanism and (b) structure of the device. Reprinted from Sens. Actuators, B, Vol. 260, Kang, Y.-T., Kim, Y. J., Bu, J., Chen, S., Cho, Y., Lee, Hyun M., Ryu, C. J., Lim, Y., Han, S.-W. Epithelial and mesenchymal circulating tumor cell isolation and discrimination using dual-immunopatterned device with newly developed anti-63B6 and anti-EpCAM, pp 320-330 (ref 37). Copyright 2018, with permission from Elsevier. $(\mathrm{B}, \mathrm{C})$ Design of a ligand decorated cell membrane mimetic surface for blood cell repellence and tumor cell capture. Reproduced from Li, T.; Li, N.; Ma, Y.; Bai, Y.-J.; Xing, C.-M.; Gong, Y.-K. J. Mater. Chem. B 2019, 7, 6087-6098 (ref 39), with permission of The Royal Society of Chemistry. (D) Capture strategy using Carpet Chip. Schematic of the CTC Carpet Chips connected in series. Rare CTCs were captured simultaneously from the peripheral blood of pancreatic cancer patients by using antiEpCAM and anti-CD133 antibodies in two different chips. Reproduced from Profiling Heterogeneous Circulating Tumor Cells (CTC) Populations in Pancreatic Cancer Using a Serial Microfluidic CTC Carpet Chip, Zeinali, M.; Murlidhar, V.; Fouladdel, S.; Shao, S.; Zhao, L.; Cameron, H.; Bankhead, A., III; Shi, J.; Cuneo, K. C.; Sahai, V.; Azizi, E.; Wicha, M. S.; Hafner, M.; Simeone, D. M.; Nagrath, S., Adv. Biosyst., Vol. 2, Issue 12 (ref 41). Copyright 2018 Wiley. (E) CTC Carpet Chip optimization with cell lines showing: (a) capture efficiency of cell lines with various levels of EpCAM expression, (b) an image showing dual CTC Carpet Chip, (c) capture efficiency of cancer cells spiked into blood with or without antibodies in the dual chips, (d) SEM image of the chip with captured cancer cells, and (e) confocal image of a $\mathrm{CK}+$ cancer cells. Reproduced from Profiling Heterogeneous Circulating Tumor Cells (CTC) Populations in Pancreatic Cancer Using a Serial Microfluidic CTC Carpet Chip, Zeinali, M.; Murlidhar, V.; Fouladdel, S.; Shao, S.; Zhao, L.; Cameron, H.; Bankhead, A., III; Shi, J.; Cuneo, K. C.; Sahai, V.; Azizi, E.; Wicha, M. S.; Hafner, M.; Simeone, D. M.; Nagrath, S., Adv. Biosyst., Vol. 2, Issue 12 (ref 41). Copyright 2018 Wiley. (F) Circulating Plasma Cells (CPC) selection device: (a) schematic of the CPC selection device, (b) SEM image of the sinusoidal channels fabricated in a 
thermoplastic, (c) image of DAPI stained affinity-selected RPMI-8226 cells, and (d) schematic of the CPCs selection process with anti-CD138 antibodies enzymatically cleaved following isolations thereby releasing intact cells. Reprinted from Isolation of Circulating Plasma Cells From Blood of Patients Diagnosed with Clonal Plasma Cell Disorders using Cell Selection Microfluidics, Integrative Biology, Vol. 10, Issue 2 (ref 42). Copyright 2018 Oxford University Press. 

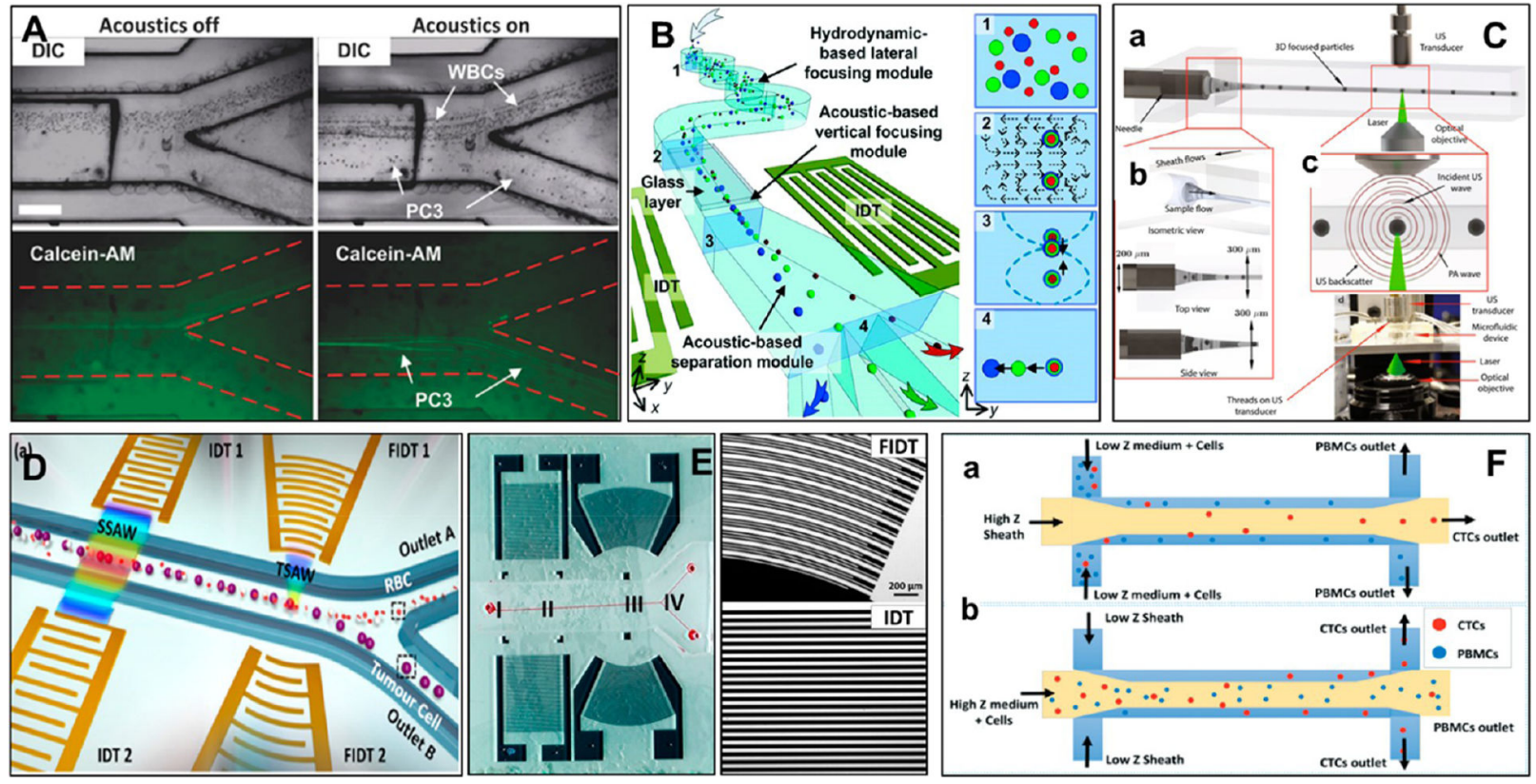

Figure 2.

Acoustofluidic and acoustophoretic methods for cell sorting. (A) Sorting of PC3 cancer cells from WBCs. Following acoustic field activation, cancer cells are pushed toward the bottom collection outlet while the majority of the WBCs continue flowing to the waste outlet. Reproduced from Circulating Tumor Cell Phenotyping via High-Throughput Acoustic Separation, Wu, M.; Huang, P.-H.; Zhang, R.; Mao, Z.; Chen, C.; Kemeny, G.; Li, P.; Lee, A. V.; Gyanchandani, R.; Armstrong, A. J.; Dao, M.; Suresh, S.; Huang, T. J. Small, Vol. 14, Issue 32 (ref 51). Copyright 2018 Wiley. (B) 3D acoustofluidic tweezers (3D-AFT) sorting device. Particles are sorted to multiple outlets under the combined effects of acoustics and hydrodynamics. Reproduced from Wu, M.; Chen, K.; Yang, S.; Wang, Z.; Huang, P.-H.; Mai, J.; Li, Z.-Y.; Huang, T. J. Lab Chip 2018, 18, 3003-3010 (ref 52), with permission of The Royal Society of Chemistry. (C) Schematic of the acoustic flow cytometry system: (a) microfluidic device with collinearly aligned US transducer and laser focusing optical objective, (b) hydrodynamic 3D flow focusing in the microfluidic device, (c) magnified view of a collinearly aligned transducer and laser beam interacting with a particle and producing backscatter and PA waves, and (d) an experimental setup with the laser focused on the interrogation zone. Reproduced with permission from Gnyawali, V.; Strohm, E. M.; Wang, J.-Z.; Tsai, S. S. H.; Kolios, M. C.Sci Rep 2019, 9, 1585 (ref 53). Copyright 2019, Springer Nature. (D) Schematic of a multistage device for tumor cell isolation. The blood cells and tumor cells are collected from outlet A and outlet B. Reprinted from Sens. Actuators, B, Vol. 258, Wang, K., Zhou, W., Lin, Z., Cai, F., Li, F., Wu, J., Meng, L., Niu, L., Zheng, H., Sorting of tumor cells in a microfluidic device by multistage surface acoustic waves, pp 1174-1183 (ref 54) Copyright 2018, with permission from Elsevier. (E) Optical imaging indicated the positions of the regions (I-IV) for monitoring the distribution and trajectory of samples within the standing surface acoustic waves and traveling surface acoustic wave fields. Top right, finger pairs of the circular interdigital transducers; and bottom right, interdigital transducers on the substrate. Reprinted from Sens. Actuators, B, Vol. 258, Wang, 
K., Zhou, W., Lin, Z., Cai, F., Li, F., Wu, J., Meng, L., Niu, L., Zheng, H., Sorting of tumor cells in a microfluidic device by multistage surface acoustic waves, pp 1174-1183 (ref 54) Copyright 2018, with permission from Elsevier. (F) CTCs sorting from PBMCs, when CTCs are of higher (a) and lower (b) acoustic impedance than that of PBMCs. Reproduced from Karthick, S.; Pradeep, P. N.; Kanchana, P.; Sen, A. K. Lab Chip 2018, 18, 3802-3813 (ref 55), with permission of the Royal Society of Chemistry. 

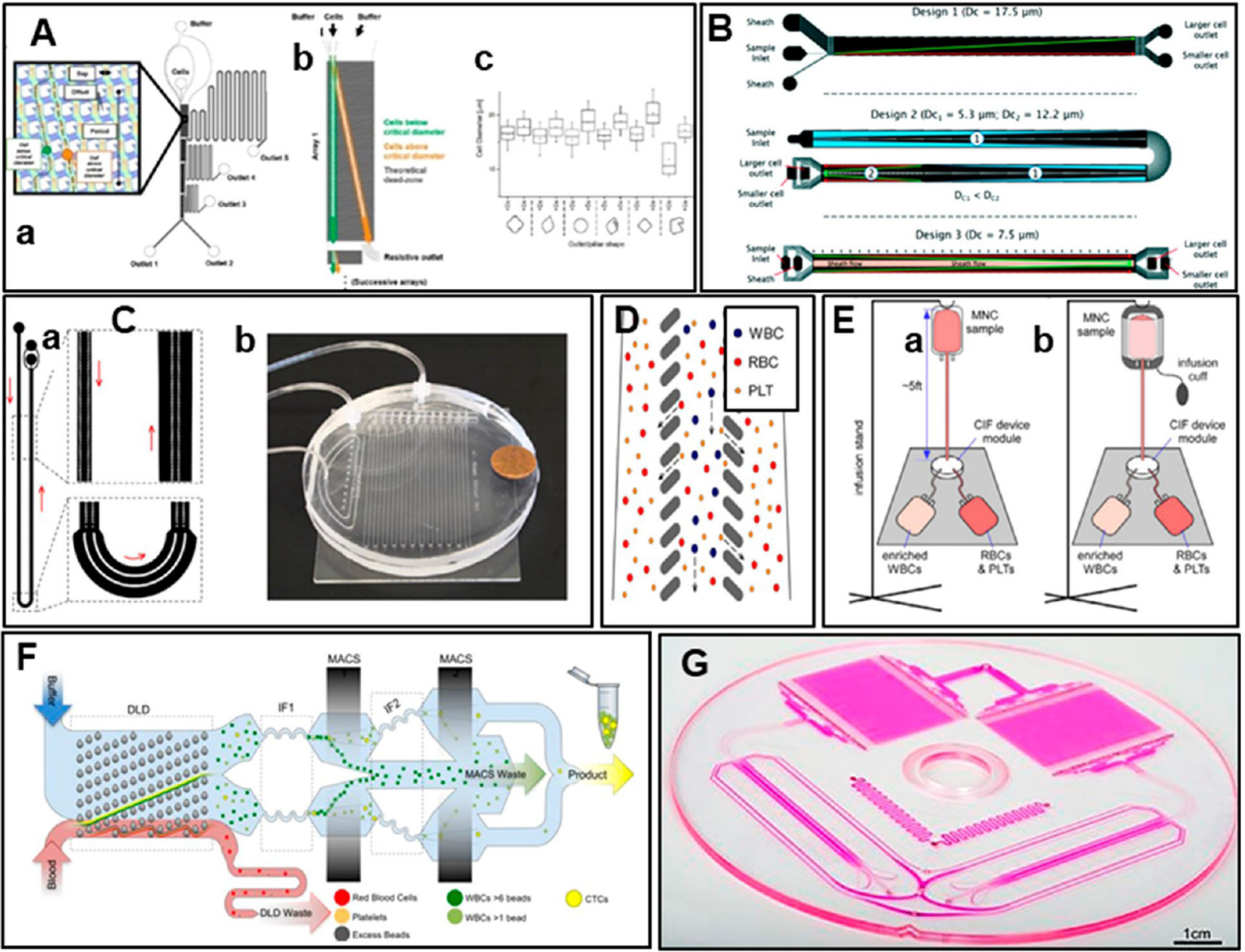

Figure 3.

(A) DLD device. (a) Cascading design with four active regions and five outlets for highresolution size-based cell sorting. (b) Device design considerations to improve sorting resolution including a wide theoretical cell fractioning unit with wide and long post arrays to introduce sorting corrections through redundancy, and buffer flow along outer walls to eliminate edge effects. Outlet resistances were COMSOL modeled to ensure vertical flow. (c) Evaluation of different pillar shapes in binary DLD devices and the effects of triangular and tumbling structures. Reproduced from Gomis, S.; Labib, M.; Coles, B. L. K.; van der Kooy, D.; Sargent, E. H.; Kelley, S. O. ACS Appl. Mater. Interfaces 2018, 10, 34811-34816 (ref 81). Copyright 2018 American Chemical Society. (B) Diagram of the three different DLD device designs. Design 1: hydrodynamically focused particles form a single flow stream. Design 2: all particles move toward the outer channel wall followed by change in the direction of the micropillar array that results in displacement of only larger particles. Design 3: combined principles used in designs 1 and 2. Reproduced from Xavier, M.; Holm, S. H.; Beech, J. P.; Spencer, D.; Tegenfeldt, J. O.; Oreffo, R. O. C.; Morgan, H. Lab Chip 2019, 19, 513-523 (ref 82), with permission of The Royal Society of Chemistry. (C) (a) Schematic of a controlled incremental filtration device and (b) an assembled microfluidic module with 12 multiplexed devices. Reprinted from Cytotherapy, Vol. 21, Strachan, B. C., Xia, H. U. I., Vörös, E., Gifford, S. C., Shevkoplyas, S. S., Improved expansion of T cells in culture when 
isolated with an equipment-free, high-throughput, flow-through microfluidic module versus traditional density gradient centrifugation, pp 234-245 (ref 83). Copyright 2019, with permission from Elsevier. (D) Schematic of the CIF design with slanted posts and the direction of flow from top to bottom. Reprinted from Cytotherapy, Vol. 21, Strachan, B. C., Xia, H. U. I., Vörös, E., Gifford, S. C., Shevkoplyas, S. S., Improved expansion of T cells in culture when isolated with an equipment-free, high-throughput, flow-through microfluidic module versus traditional density gradient centrifugation, pp 234-245 (ref 83). Copyright 2019, with permission from Elsevier. (E) CIF can operate in two ways: (a) hanging a bag with the input sample $>5 \mathrm{ft}$ above the module or (b) by compression of the sample bag with an infusion cuff. Reprinted from Cytotherapy, Vol. 21, Strachan, B. C., Xia, H. U. I., Vörös, E., Gifford, S. C., Shevkoplyas, S. S., Improved expansion of T cells in culture when isolated with an equipment-free, high-throughput, flow-through microfluidic module versus traditional density gradient centrifugation, pp. 234-245 (ref 83). Copyright 2019, with permission from Elsevier. (F) Schematic and $(\mathrm{G})$ image of the inertial focusing-enhanced microfluidic system for cell processing. In this device, sorting of rare cells is accomplished by negative selection of prelabeled WBCs with immunomagnetic beads. First, the DLD device separates nucleated cells from RBC, platelets, and unbound magnetic beads. In the next step, the cells are accelerated through an inertial focusing device. The aligned tagged cells pass through a magnetic field where they are pushed toward the center of the channel. Remaining untagged cells are refocused in a second inertial focusing device and then entered a different region of the magnetic field leading to the removal of all labeled cells. Reproduced from Fachin, F.; Spuhler, P.; Martel-Foley, J. M.; Edd, J. F.; Barber, T. A.; Walsh, J.; Karabacak, M.; Pai, V.; Yu, M.; Smith, K.; Hwang, H.; Yang, J.; Shah, S.; Yarmush, R.; Sequist, L. V.; Stott, S. L.; Maheswaran, S.; Haber, D. A.; Kapur, R.; Toner, M. Sci. Rep., 2017, 7, 1-11 (ref 84). Copyright 2017 Springer Nature. 

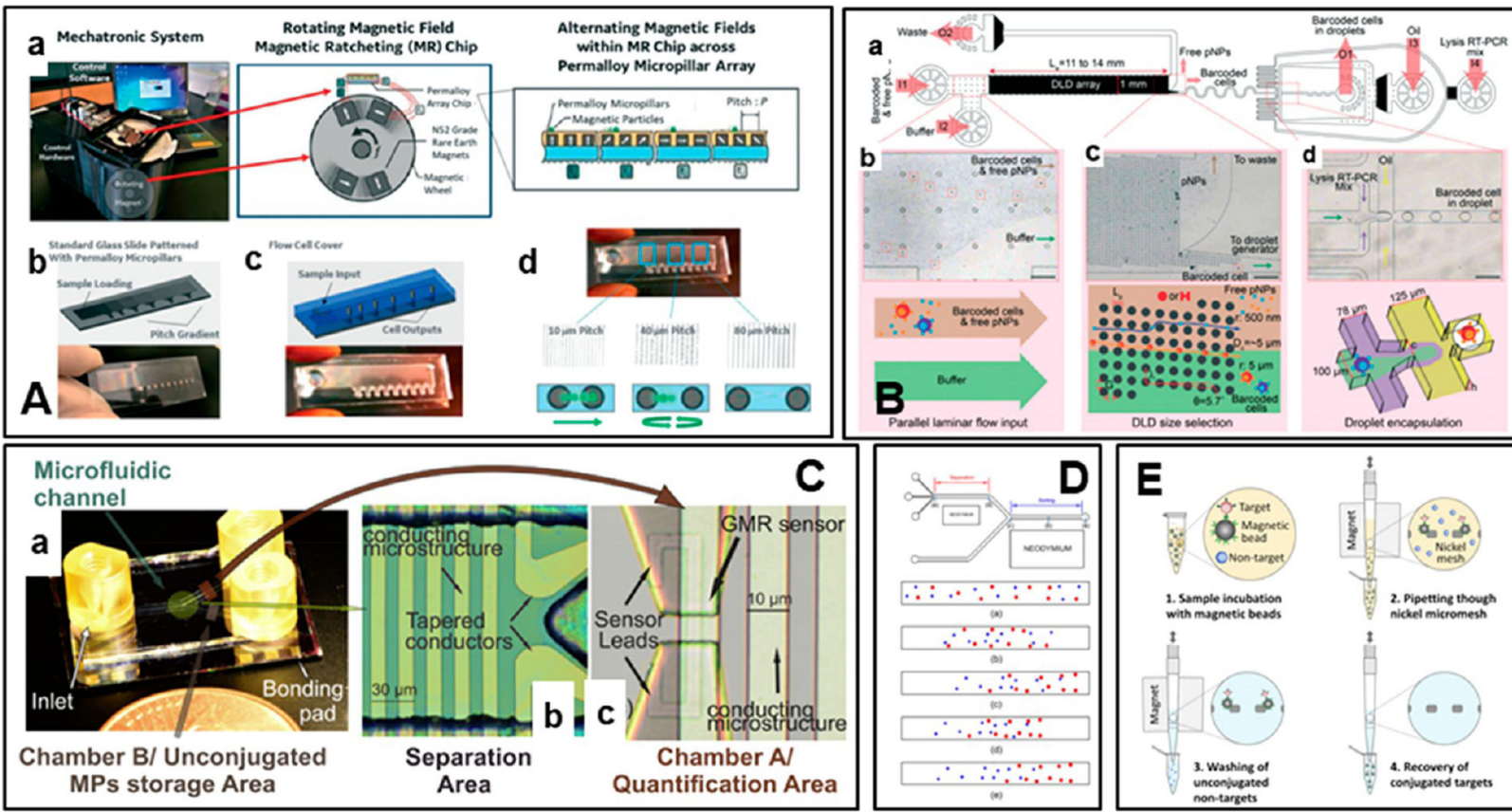

Figure 4.

(A) Mechatronic system (a) used to control cell ratcheting across the device. (b)

Paramagnetic pillars patterned on a glass slide and (c) a flow cell. (d) The $1 \mu \mathrm{m}$ particles moved across the ratchet and achieved a "critical pitch" at $40 \mu \mathrm{m}$ pillar pitch. Reproduced from Murray, C.; Miwa, H.; Dhar, M.; Park, D. E.; Pao, E.; Martinez, J.; Kaanumale, S.; Loghin, E.; Graf, J.; Rhaddassi, K.; Kwok, W. W.; Hafler, D.; Puleo, C.; Di Carlo, D. Lab Chip 2018, 18, 2396-2409 (ref 30), with permission of The Royal Society of Chemistry. (B) Microfluidic device for MATE-seq. (a) The device integrated a DLD array and a droplet generator with inputs for barcoded cells-free pNPs mixture, buffer, oil, and lysis/RT-PCR mix, and outputs for the water-in-oil droplets and waste. (b) The barcoded cells and free pNPs were flowed in parallel with RT-PCR buffer (no mixing). (c) The barcoded cells after DLD were displaced toward the droplet generator (free pNPs removed). (d) Barcoded cells were encapsulated in droplets with lysis and RT-PCR mix. Reproduced from Ng, A. H. C.; Peng, S.; Xu, A. M.; Noh, W. J.; Guo, K.; Bethune, M. T.; Chour, W.; Choi, J.; Yang, S.; Baltimore, D.; Heath, J. R. Lab Chip 2019, 19, 3011-3021 (ref 17), with permission of The Royal Society of Chemistry. (C) Microfluidic utilizing giant magnetoresistance (GMR) integrated sensors. (a) Chip with microfluidic channel and storage chambers; (b) micrograph of the separation area inside the channel showing also the parallel conducting microstructures and the tapered conductors for the isolation of cells; and (c) micrograph of a chamber and quantification area including the GMR sensor, the conducting microstructure on top of the sensor for the attraction and magnetization of the MPs, and parallel conducting microstructures for manipulation of the magnetically labeled cancer cells. Reprinted from Sens. Actuators, B, Vol. 241, Kokkinis, G., Cardoso, S., Keplinger, F., Giouroudi, I., Microfluidic platform with integrated GMR sensors for quantification of cancer cells, pp 438-445 (ref 88). Copyright 2017, with permission from Elsevier. (D) Schematic of microparticle distribution within the microfluidic using dual-neodymium magnet-based negative magnetophoresis. Reprinted from Kye, H. G.; Park, B. S.; Lee, J. M.; Song, M. G.; 
Song, H. G.; Ahrberg, C. D.; Chung, B. G. Sci. Rep. 2019, p 9502 (ref 89). Copyright 2019 Springer Nature. (E) Magnetizable micropipette tip for MACS, so-called "MACS-Tip" and standard operating procedure. Reprinted from Sens. Actuators, B, Vol. $272 \mathrm{Oh}$, S., Jung, Su H., Seo, H.,Min, M., Kim, B., Hahn, Y., Kang, J. H., Choi, S., Magnetic activated cell sorting (MACS) pipet tip for immunomagnetic bacteria separation, pp 324-330 (ref 24). Copyright 2018, with permission from Elsevier. 

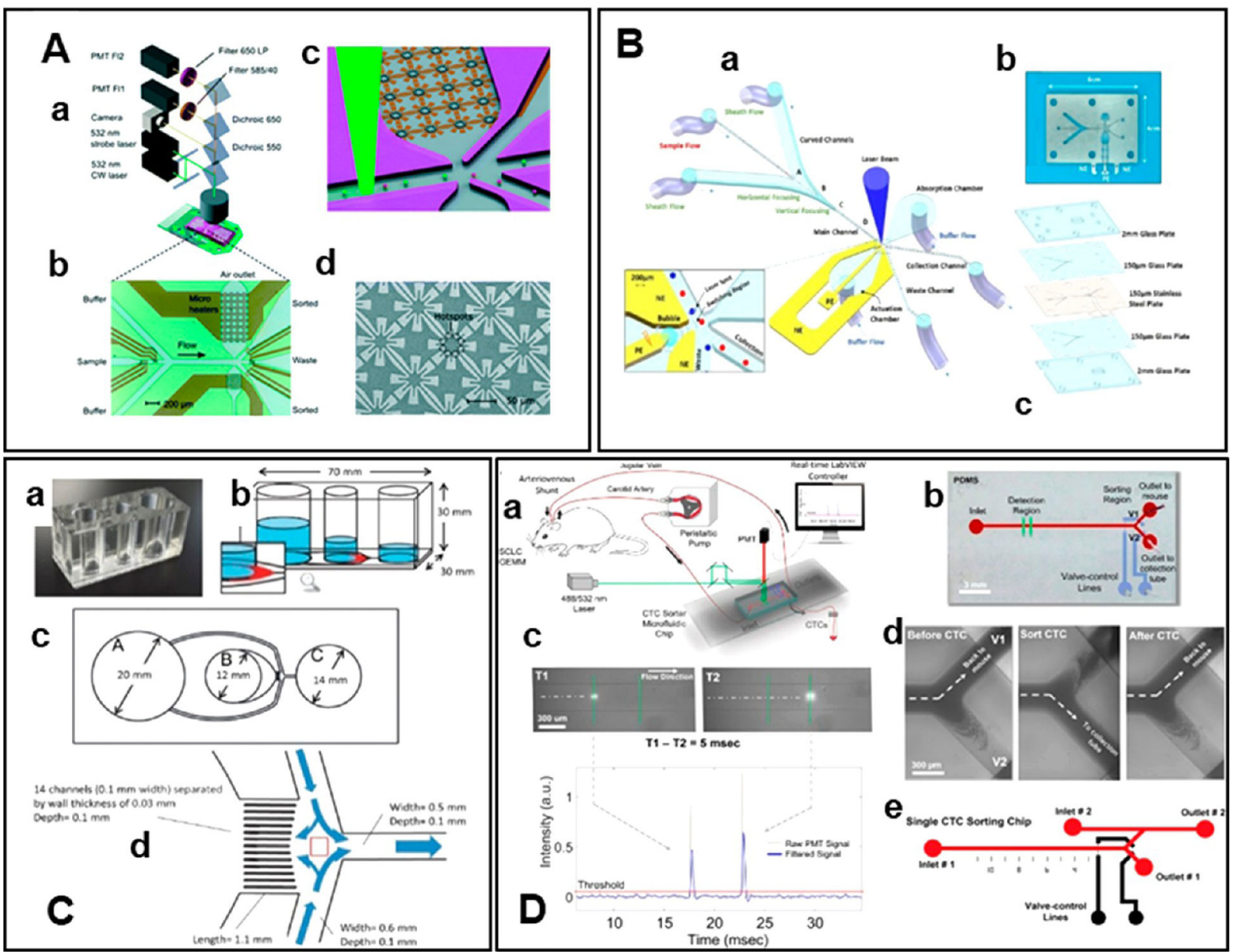

Figure 5.

(A) Schematic of a microfluidic cell sorter: (a) schematic of optical detection setup, (b) micrograph of sorter chip with jet flow generation chamber and microheaters, (c) illustration of the sorting method, red cells of interest were sorted with an upper jet flow generator into a lower outlet channel and green cells flowed to the waste, and (d) SEM of microheaters.

Reproduced from de Wijs, K.; Liu, C.; Dusa, A.; Vercruysse, D.; Majeed, B.; Tezcan, D. S.; Blaszkiewicz, K.; Loo, J.; Lagae, L. Lab Chip 2017, 17, 1287-1296 (ref 94), with permission of The Royal Society of Chemistry. (B) Spark-generated microbubble cell sorter: (a) microfluidic for 3D hydrodynamic focusing and sorting. When a target sample passed through the laser spot, a spark discharge was triggered, and the cavitation microbubble deflected the identified sample into the collection channel, (b) photograph of the device, and (c) chip was composed of middle part made of stainless steel and the others were glass. Reproduced from Spark-generated microbubble cell sorter for microfluidic flow cytometry, Zhao, J.; You, Z., Cytometry A, 93, pp 222-231 (ref 95). Copyright 2018 Wiley. (C) Microfluidic sperm sorter: (a) photograph of the device made of PDMS and glass, (b) chambers A for sorting medium, B for semen seeding, and C for sperm collection, (c) medium flowing out from chamber A was supplied into chambers B and C, (d) microchannel network showing the junction area (red square). The 14 microchannels formed a laminar flow distribution into a crescent-shaped diffuser enabling more motile 
spermatozoa to swim into this zone and travel the distance along the multiple microchannels. Reproduced from Nagata, M. P. B.; Endo, K.; Ogata, K.; Yamanaka, K.; Egashira, J.; Katafuchi, N.; Yamanouchi, T.; Matsuda, H.; Goto, Y.; Sakatani, M.; Hojo, T.; Nishizono, H.; Yotsushima, K.; Takenouchi, N.; Hashiyada, Y.; Yamashita, K. Proc. Natl. Acad. Sci. U.S.A., 115, pp E3087-E3096 (ref 98). Copyright 2018 National Academy of Sciences. (D) Microfluidic sorter for animal longitudinal CTC studies: (a) pump withdraws blood from an artery of a mouse and directs blood into a chip. CTC-depleted blood returns to the jugular vein of the mouse via a second cannula. (b) Top-view image of the microfluidic chip with valve actuation lines, (c) fluorescent CTC emits two pulses of light detected by a PMT. Computer-controlled pneumatic valves redirect fluorescent CTCs to a collection tube. A low-pass filter was applied to the raw data for identifying true peaks. (d) CTC sorting in real time, (e) enrichment of CTCs by a secondary sorting chip designed with a parallel channel to flush CTCs into wells containing lysis buffer. Reproduced from Hamza, B.; Ng, S. R.; Prakadan, S. M.; Delgado, F. F.; Chin, C. R.; King, E. M.; Yang, L. F.; Davidson, S. M.; DeGouveia, K. L.; Cermak, N.; Navia, A. W.; Winter, P. S.; Drake, R. S.; Tammela, T.; Li, C. M.-C.; Papagiannakopoulos, T.; Gupta, A. J.; Shaw Bagnall, J.; Knudsen, S. M.; Vander Heiden, M. G. et al. Proc. Natl. Acad. Sci. U.S.A. 116, pp 2232-2236 (ref 100). Copyright 2019 National Academy of Sciences. 

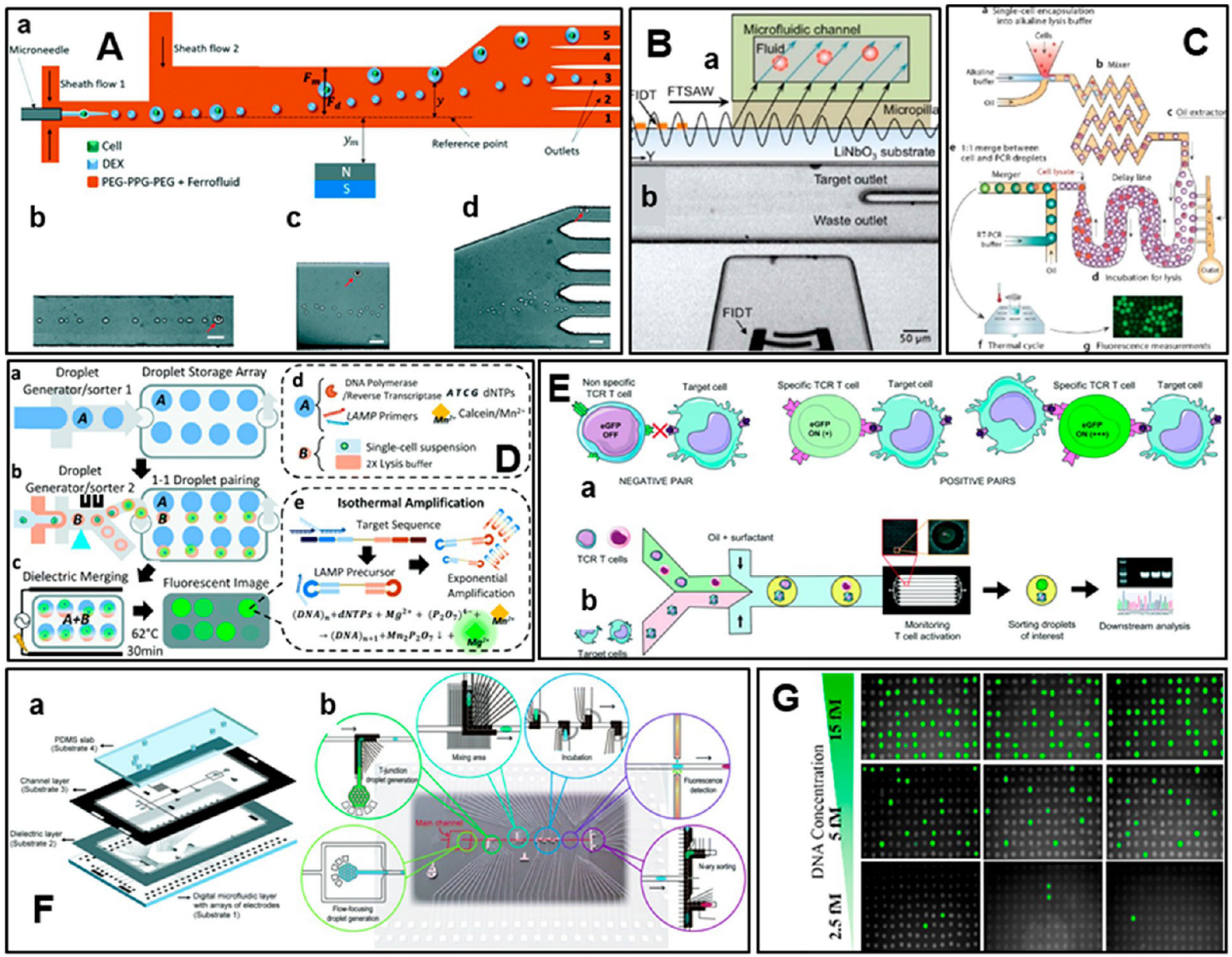

Figure 6.

(A) Diamagnetic droplet microfluidic: (a) sorting of cell-containing droplets from empty droplets, (b) size distinction between a particle-encapsulating droplet and empty droplets, (c) region of high magnetic field gradient with droplets deflected based on their size, (d) sorting of droplets into different reservoirs. Reproduced from Navi, M.; Abbasi, N.; Jeyhani, M.; Gnyawali, V.; Tsai, S. S. H. Lab Chip 2018, 18, 3361-3370 (ref 115), with permission of The Royal Society of Chemistry. (B) Fluorescence-activated droplet sorting (FADS) system: (a) micrograph of the acoustic sorting system and the view of the sorting region. Reproduced from Li, P.; Ma, Z.; Zhou, Y.; Collins, D. J.; Wang, Z.; Ai, Y. Anal. Chem. 2019, 91, 99709977 (ref 116). Copyright 2019 American Chemical Society. (C) Schematic of a single-cell RT-PCR device integrating lysis and reagent addition. The device produced droplets ready for amplification. Cells were encapsulated with lysis buffer (a) and content mixed (b). Excess oil removed from the emulsion (c), and droplets packed for the incubation for a controlled time (d). Droplets with lysed-cells were merged with droplets containing PCR buffer for amplification (e). Cells expressing the target mRNA (f), yielded fluorescent TaqMan-positive signal (g). Reproduced from Kim, S. C.; Clark, I. C.; Shahi, P.; Abate, A. R. Anal. Chem. 2018, 90, 1273-1279 (ref 117). Copyright 2018 American Chemical Society. (D) Schematics of single-cell RT-LAMP assay using Sort N' Merge platform: (a) droplets containing RT-LAMP reactants were generated, (b) droplets containing single-cell 
and lysis buffer were generated and sorted into the storage device, (c) paired droplets were merged by electrohydrodynamic forces. RT-LAMP reaction performed followed by imagingbased fluorescence measurements, (d) content of the droplets, and (e) principle of RT-LAMP reactions. Reproduced from Chung, M. T.; Kurabayashi, K.; Cai, D. Lab Chip 2019, 19, 2425-2434 (ref 118) with permission of The Royal Society of Chemistry. (E) Droplet based platform for the screening of specific TCR T cells: (a) only specific TCR T cells are activated upon recognition of their cognate antigen, triggering the expression of eGFP and (b) schematic of the workflow. Droplets containing activated T cells were sorted for downstream molecular analysis. Reproduced from Segaliny, A. I.; Li, G.; Kong, L.; Ren, C.; Chen, X.; Wang, J. K.; Baltimore, D.; Wu, G.; Zhao, W. Lab Chip 2018, 18, 3733-3749 (ref 119), with permission of The Royal Society of Chemistry. (F) Integrated digital-droplet microfluidic device and (a) view of multilayer construct of the device and (b) image of the device and the schema of operations. Reproduced from Ahmadi, F.; Samlali, K.; Vo, P. Q. N.; Shih, S. C. C. Lab Chip 2019, 19, 524-535 (ref 120), with permission of The Royal Society of Chemistry. (G) Digital detection of lambda DNA with three different concentrations of templates. Reproduced from Li, X.; Zhang, D.; Zhang, H.; Guan, Z.; Song, Y.; Liu, R.; Zhu, Z.; Yang, C. Anal. Chem. 2018, 90, 2570-2577 (ref 121). Copyright 2018 American Chemical Society. 


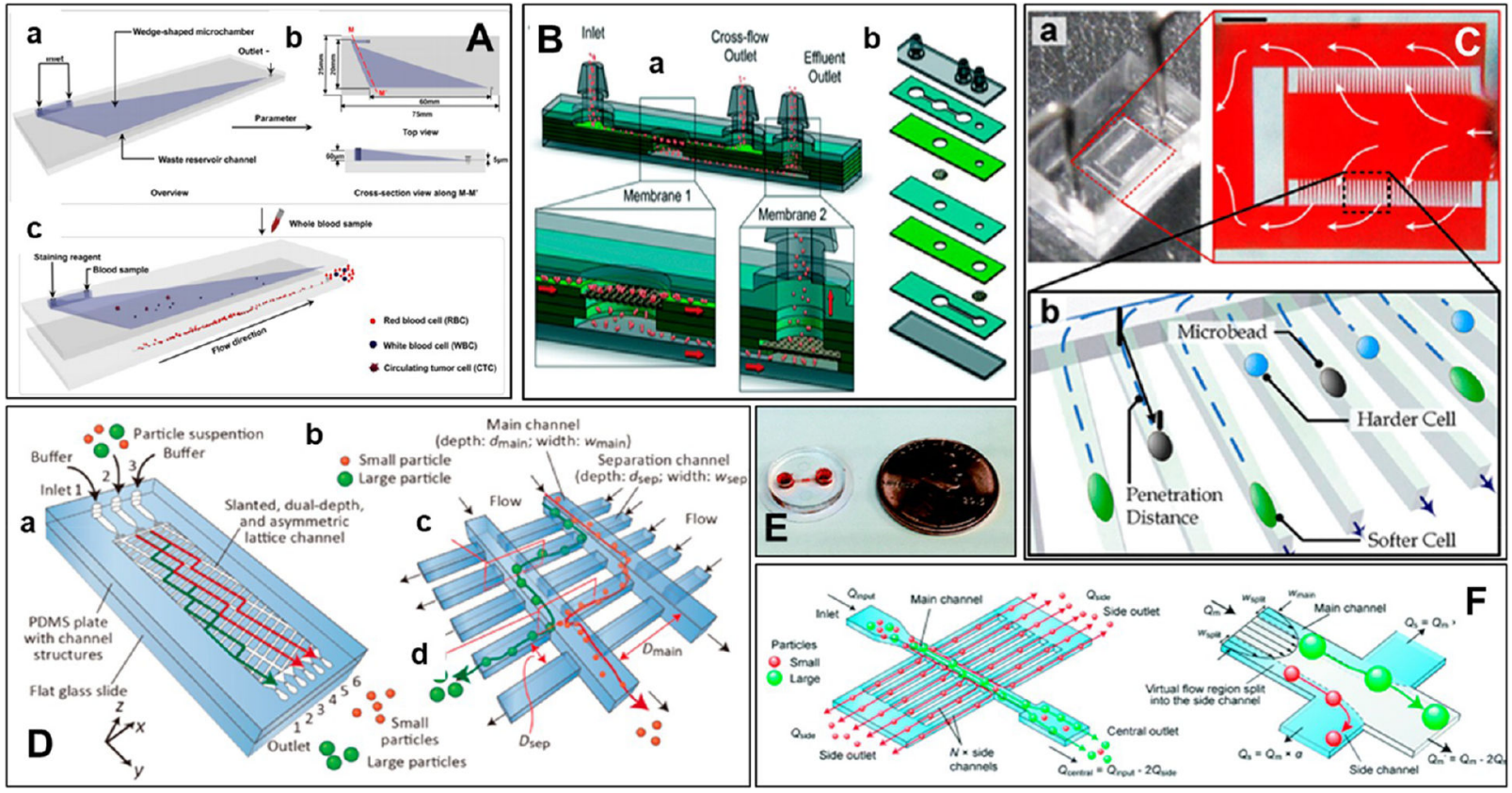

Figure 7.

(A) Wedge-shaped microfuidic chip: (a) overview and (b) dimensions of the microfuidic chip and (c) schematic diagram of CTC isolation using a wedge-shaped microchamber. Reproduced from Yang, C.; Zhang, N.; Wang, S.; Shi, D.; Zhang, C.; Liu, K.; Xiong, B. J. Transl. Med. 2018, 16, p 139 (ref 132). Copyright 2018 Springer Nature. (B) Microfluidic filter device: (a) schematic of device with two microporous membranes and (b) exploded view showing design of the chip with seven layers, including channel, vias, and two layers to seal the top and bottom of the device. Reproduced from Qiu, X.; Lombardo, J. A.; Westerhof, T. M.; Pennell, M.; Ng, A.; Alshetaiwi, H.; Luna, B. M.; Nelson, E. L.; Kessenbrock, K.; Hui, E. E.; Haun, J. B. Lab Chip 2018, 18, 2776-2786 (ref 133), with permission of The Royal Society of Chemistry. (C) "Confining" device: (a) microscopic image of the flow region containing two series of confining microchannels. The fluid flow is indicated by white arrows. (b) Concept of the elasticity-based cell classification; the position of a microbead inside the microchannels reflected its elasticity. Reproduced from Ren, J.; Li, J.; Li, Y.; Xiao, P.; Liu, Y.; Tsang, C. M.; Tsao, S. W.; Lau, D.; Chan, K. W. Y.; Lam, R. H. W. ACS Biomater. Sci. Eng. 2019, 5, 3889-3898 (ref 134). Copyright 2019 American Chemical Society. (D) Dual depth, lattice-shaped channel network for (a) particle sorting, (b) transport of particles in the lattice region, and (c, d) particle movement between shallow and deep channels and into the main channels. Reproduced from Yanai, T.; Ouchi, T.; Yamada, M.; Seki, M. Micromachines (Basel) 2019, 10 ( 6), 425 (ref 135). Coyright 2019 The authors. (E) Pump-free cell trapping device bonded to a glass coverslip. Reproduced from Weng, L.; Ellett, F.; Edd, J.; Wong, K. H. K.; Uygun, K.; Irimia, D.; Stott, S. L.; Toner, M. Lab Chip 2017, 17, 4077-4088 (ref 136), with permission of The Royal Society of Chemistry. (F) Diagram showing the strategy for cell sorting based on the HDF scheme. Reproduced from Ozawa, R.; Iwadate, H.; Toyoda, H.; Yamada, M.; Seki, M. Lab Chip 2019, 19, 1828-1837 (ref 137), with permission of The Royal Society of Chemistry. 


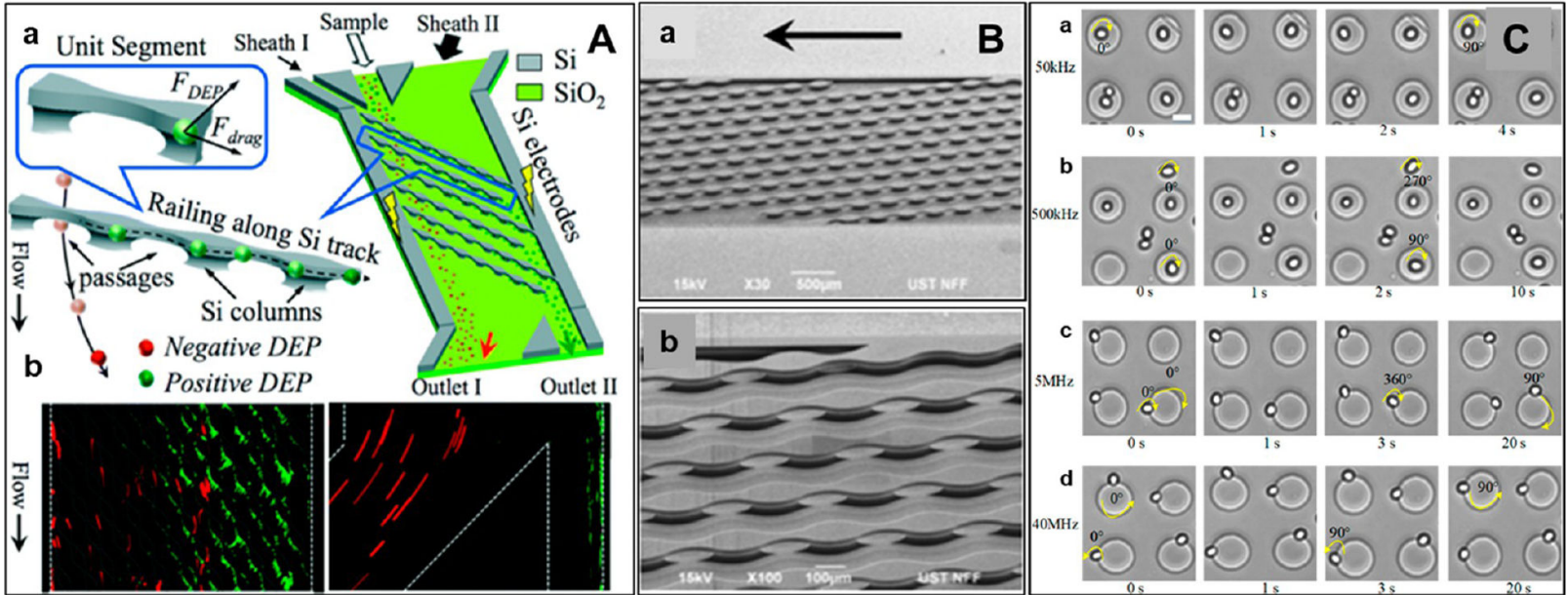

Figure 8.

(A) Device utilizing DEP and hydrodynamic drag forces for cell sorting: (a) schematic of the concept of railing target cells (green) along a track (electrode) under pDEP and hydrodynamic drag and (b) fluorescence images of the tracks and the outlets during cell sorting. HCT116 cells (green) are sorted from $10 \mu \mathrm{m}$ polystyrene beads (red). Reproduced from Xing, X.; Ng, C. N.; Chau, M. L.; Yobas, L. Lab Chip 2018, 18, 3760-3769 (ref 147), with permission of The Royal Society of Chemistry. (B) SEM images (a) of the device's flow chamber and (b) a close-up view. Reproduced from Xing, X.; Ng, C. N.; Chau, M. L.; Yobas, L. Lab Chip 2018, 18, 3760-3769 (ref 147), with permission of The Royal Society of Chemistry. (C) Time-lapse images of yeast cells (a) rotational motions at the center of wireless electrodes ( $A=5 \mathrm{~V}, f=50 \mathrm{kHz}$ ). (b) Rotational motions at the center of wireless electrodes and in the center area where floating electrodes were absent $(A=5 \mathrm{~V}, f=500$ $\mathrm{kHz}$ ). (c) Clockwise rotation on their axes and propulsion around the wireless electrode edges ( $A=5 \mathrm{~V}, f=5 \mathrm{MHz}$ ). (d) Counterclockwise rotation on their axes and propulsion around wireless electrode edges ( $A=5 \mathrm{~V}, f=40 \mathrm{MHz}$ ). Reproduced from Wu, Y.; Ren, Y.; Tao, Y.; Hou, L.; Jiang, H. Anal. Chem. 2018, 90, 11461-11469 (ref 148). Copyright 2018 American Chemical Society. 

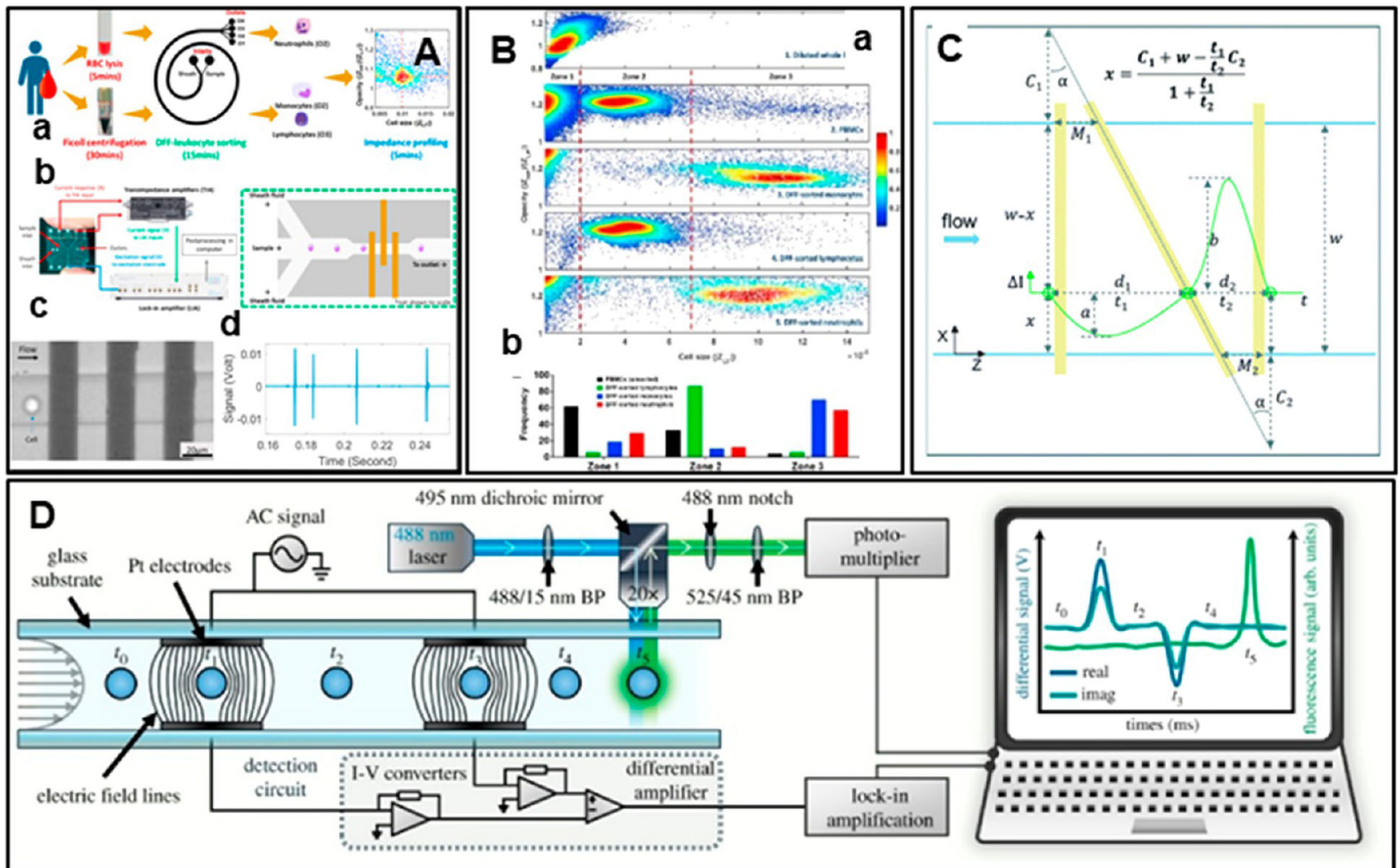

Figure 9.

(A) Dean flow fractionation device: (a) workflow for leukocyte impedance phenotyping for sample preprocessing, DFF leukocyte sorting, and impedance profiling, (b) image of the microfluidic chips, (c) optical image of single cells flowing through the electrodes in the detection region, and (d) measurement of multiple events from single cells. Reprinted from Biosens. Bioelectron., Vol. 118, Petchakup, C.; Tay, H. M.; Yeap, W. H.; Dalan, R.; Wong, S. C.; Li, K. H. H.; Hou, H. W. Label-free leukocyte sorting and impedance-based profiling for diabetes testing, pp 195-203 (ref 155). Copyright 2018, with permission from Elsevier. (B) Impedance profiling of different blood cell samples: (a) density scatter plot of cell size (| $Z_{\mathrm{LF}}, \mathrm{V}$ ) versus opacity of diluted whole blood, PBMCs, DFF-sorted monocytes, DFF-sorted lymphocytes, and DFF-sorted neutrophils and (b) frequency distribution of different leukocyte subtypes. Reprinted from Biosens. Bioelectron., Vol. 118, Petchakup, C.; Tay, H. M.; Yeap, W. H.; Dalan, R.; Wong, S. C.; Li, K. H. H.; Hou, H. W. Label-free leukocyte sorting and impedance-based profiling for diabetes testing, pp 195-203 (ref 155). Copyright 2018, with permission from Elsevier. (C) Sensing area showing a simple analytical expression for the lateral position measurement of the flowing particles (derived from the electrical signal, positions of the flowing particles, electrodes, and microchannel).

Reproduced from Yang, D.; Ai, Y. Lab Chip 2019, 19, 3609-3617 (ref 156), with permission of The Royal Society of Chemistry. (D) Schematic of a microfluidic impedance cytometer showing impedance and fluorescence detection sections. The fluorescence from cells was measured simultaneously with impedance allowing direct correlation of electrical and fluorescent properties of single cells. Reproduced from Honrado, C.; Ciuffreda, L.; Spencer, D.; Ranford-Cartwright, L.; Morgan, H. J. R. Soc. Interface 2018, 15, 20180416 (ref 33), with permission of The Royal Society of Chemistry. 


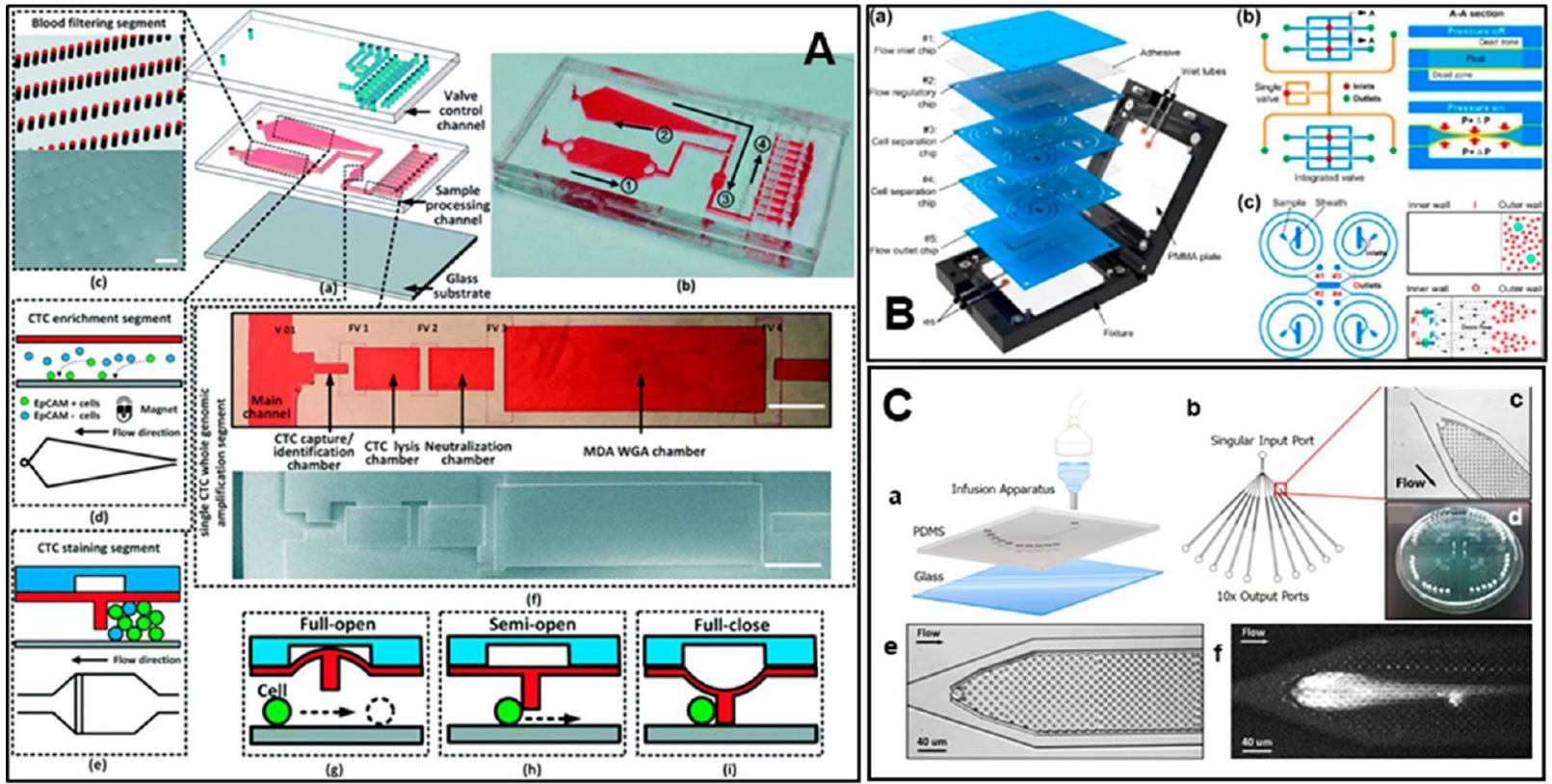

Figure 10.

(A) Microfluidic chip for CTC isolation and whole genome amplification: (a) chip consisted of 3 layers, the valve control channel, the sample processing channel, and glass substrate, (b) photograph and (c) an SEM of the blood-filtering segment, (d) enrichment segment, and (e) staining segment. (f) Photograph and SEM image of a subchannel, cell-processing chambers. (g-i) Operation of a tristate valve. Reproduced from Li, R.; Jia, F.; Zhang, W.; Shi, F.; Fang, Z.; Zhao, H.; Hu, Z.; Wei, Z. Lab Chip 2019, 19, 3168-3178 (ref 157), with permission of The Royal Society of Chemistry. (B) Integrated microfluidic Dean-flow fractionation device: (a) design of the device, (b) principle of operation of flow regulatory chip showing membrane deformation when fluidic pressures in the control channels were increased to push two elastic membranes toward the fluidic channel, and (c) principle of cell sorting. Reproduced from Zhang, X.; Zhu, Z.; Xiang, N.; Long, F.; Ni, Z. Anal. Chem. 2018, 90, 4212-4220 (ref 158). Copyright 2018 American Chemical Society. (C) GAMA device:

(a) view of the microfluidic device and an infusion apparatus connected to the input port, (b) valveless 10-channel device, a product from each channel is separately collected, (c) micrograph of the cell capture region, (d) 10-channel devices bonded to a glass silica wafer, (e) image of an intact and (f) lysed single cell, and fluorescence observed from YOYO-1 stained genomic DNA. Reproduced from Tian, H. C.; Benitez, J. J.; Craighead, H. G. PLoS One 2018, 13, e0191520 (ref 14) with permission from PLOS. 